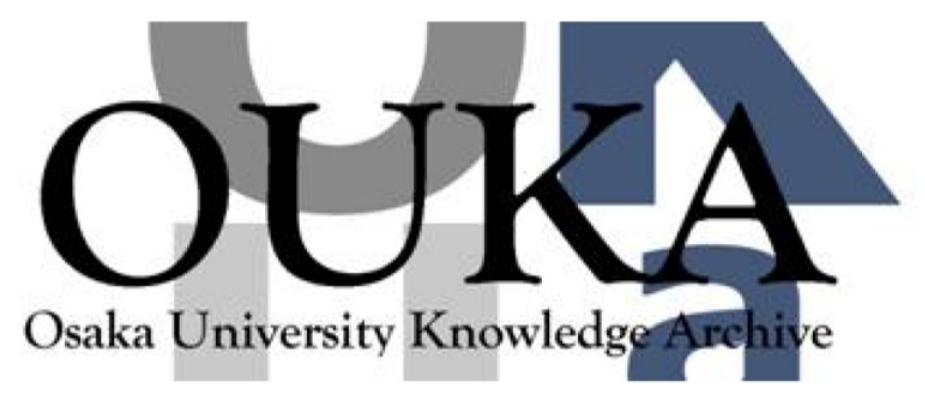

\begin{tabular}{|c|l|}
\hline Title & $\begin{array}{l}\text { Production location of multinational firms } \\
\text { under transfer pricing: the impact of the } \\
\text { arm's length principle }\end{array}$ \\
\hline Author(s) & Kato, Hayato; Okoshi, Hirofumi \\
\hline Citation & $\begin{array}{l}\text { International Tax and Public Finance. 26(4) } \\
\text { p. 835-p. 871 }\end{array}$ \\
\hline Issue Date & $2019-08-15$ \\
\hline oaire:version & AM \\
\hline URL & https://hdl.handle.net/11094/81779 \\
\hline rights & $\begin{array}{l}\text { ○ 2018, Springer Science+Business Media, LLC, } \\
\text { part of Springer Nature. }\end{array}$ \\
\hline Note & \\
\hline
\end{tabular}

Osaka University Knowledge Archive : OUKA

https://ir. Library. osaka-u. ac. jp/

Osaka University 


\title{
Production Location of Multinational Firms under Transfer Pricing: The Impact of the Arm's Length Principle*
}

\author{
Hayato Kato $^{\dagger}$ Hirofumi Okoshi ${ }^{\ddagger}$
}

October 2018

\begin{abstract}
When multinational enterprises (MNEs) separate the geographical location of affiliates, they can shift profits between the affiliates by manipulating intra-firm prices of inputs. We show that if the international tax difference between the parent and the host countries is large, MNEs choose to separately locate their affiliates in the two countries. We also investigate the impact of the arm's length principle (ALP) on the location choice, which requires that the intra-firm price of inputs should be set equal to the price of similar inputs for the independent downstream firms. The ALP may change the location choice of MNEs, bringing smaller tax revenues to the host country, but greater revenues globally.
\end{abstract}

Keywords: Multinational enterprises (MNEs); Transfer pricing; Production location choice; Intra-firm trade; Arm's length principle (ALP)

JEL classifications: F12; F23; H25; H26

${ }^{*}$ We wish to acknowledge the valuable comments from two anonymous referees and the editor, Ronald Davies. Thanks are also to David Agrawal, Jay Pil Choi, Dave Donaldson, Taiji Furusawa, Makoto Hasegawa, Andreas Haufler, Jota Ishikawa, Michael Keen, Kozo Kiyota, Yoshimasa Komoriya, Christopher Ludwig, Yasusada Murata, Ben Lockwood, Yukihiro Nishimura, Hikaru Ogawa, Toshihiro Okubo, Pascalis Raimondos, Yasuhiro Sato, Nicolas Schmitt, Yoichi Sugita, Kimiko Terai, Eiichi Tomiura, and Lorenzo Trimarchi for helpful suggestions. This paper was presented at HITS-MJT (Kanazawa Seiryo U), Hitotsubashi-Sogang Trade Workshop (Hitotsubashi U), Public Economics Workshop (U of Tokyo), Study Group on Spatial Economics (Kyushu Sangyo U), JSIE Kanto Meeting (Nihon U), International Symposium of Urban Economics and Public Economics (Osaka U), Applied Economics Workshop (Keio U), Australasian Trade Workshop (U of Auckland), 17th GEP/CEPR Annual Postgraduate Conference (U of Nottingham), Public Economics Seminar (LMU), and International Institute of Public Finance (U of Tampere). Financial supports from the Japan Society for the Promotion of Science (Grant Number: JP16J01228), the MEXT-Supported Program for the Strategic Research Foundation at Private Universities (Grant Number: JPS1391003), the Obayashi Foundation, the Japan Legislatic Society Foundation, and the German Research Foundation through GRK are gratefully acknowledged. All remaining errors are our responsibility.

${ }^{\dagger}$ Corresponding author. Faculty of Economics, Keio University, 2-15-45 Mita, Minato-ku, Tokyo, 108-8345, Japan. E-mail address: hayato.kato2@gmail.com

${ }^{\ddagger}$ Munich Graduate School of Economics, University of Munich, Seminar for Economic Policy, Akademiestr. 1/II, D-80799 Munich, Germany. E-mail address: hirofumi.okoshi1@gmail.com 


\section{Introduction}

The manner in which multinational enterprises (MNEs) organize their production structure is essential for their international strategy. As MNEs can substantially benefit from the opportunity to locate their affiliates in several countries, their location decisions depend on country-specific characteristics, such as the extent of competition and policies in host countries. Considerable research has been undertaken to investigate the determinants of MNEs' locations from both theoretical and empirical standpoints. ${ }^{1}$ Among other factors affecting the location choice, the corporate taxation prevalent in both the host and parent countries is known to have a significant impact. ${ }^{2}$

When considering a firm with a single plant, the consequence of corporate taxation is straightforward; the firm locates its production in a country with a lower tax rate to save taxes. However, the impact of taxation on MNEs' location choice is not this simple. The striking difference between MNEs with multiple plants and single-plant firms is that MNEs' transactions may take place within their organization across borders. This means that MNEs can partly control prices of intermediate goods for foreign affiliates, which are known as transfer prices, through intra-firm trade in order to reduce global tax payments. Thus, it is possible that using such a transfer pricing strategy, MNEs locate their production in a high-tax country, while exporting inputs to their affiliates located in a low-tax country.

The relationship between corporate tax rates and the location choice of MNEs using transfer pricing is not just a theoretical curiosity, but is of great importance to the modern economy. Along with the progress of economic integration, intra-firm trade has grown dramatically in recent years, which provides MNEs room for tax manipulations through transfer

\footnotetext{
${ }^{1}$ For comprehensive surveys, see Markusen (2004); Navaretti and Venables (2004); and Blonigen (2005).

${ }^{2}$ Hebous et al. (2011) show that lower corporate tax induces inflows of foreign capital irrespective of the type of investment, such as greenfield foreign direct investment and cross-border mergers and acquisitions. Voget (2011) finds that one percentage point decline in foreign effective tax rate augments the likelihood of headquarters' relocation by 0.22 percentage point. Karkinsky and Riedel (2012) and Griffith et al. (2014) investigate the link between corporate taxation and patent location.
} 
pricing. ${ }^{3,4}$ Recently, the OECD launched a project involving over 80 countries to address the tax avoidance behavior of MNEs, including transfer pricing. ${ }^{5}$ According to the OECD, revenue losses from tax avoidance by MNEs are estimated to be between $4 \%$ and $10 \%$ of global corporate income tax revenues. ${ }^{6}$ Despite the growing concern globally, limited work has been done on the interaction between MNEs' location choice and their transfer pricing strategy. The first aim of this paper is to examine how corporate tax rates affect the production location decision of MNEs using transfer pricing.

From the government's perspective, there is no doubt that steps preventing MNEs from tax manipulations are indispensable for collecting tax revenues. Many countries adopt a transfer pricing tax system to infer whether MNEs avoid tax payments. The key idea to appropriate the transaction price for related affiliates is the arm's length principle (ALP) which is set out in Article Nine of the OECD Model Tax Convention. The principle points out that conditions (e.g., price, markup or profit) of controlled transactions between related firms should be similar to those of independent transactions.

Among several methods the application of the ALP follows in practice, we focus on the comparable uncontrolled price (CUP) method, which compares the price charged for goods in a controlled transaction with the price charged for comparable goods in an uncontrolled transaction, called the arm's length price. ${ }^{7,8}$ According to the OECD guideline on transfer pricing, the CUP method is to be preferred if this and other methods can be applied in

\footnotetext{
${ }^{3}$ Bernard et al. (2010) show that over 46 percent of U.S. imports composed of intra-firm transactions in 2000. Lanz and Miroudot (2011) report that U.S. imports of intermediate products score around 50 percent in 2009. See also Slaughter (2000) and Hanson et al. (2005) for the importance of intra-firm trade.

${ }^{4}$ For (in)direct evidence on transfer pricing, see Swenson (2001); Bartelsman and Beetsma (2003); Clausing (2003); Bernard et al. (2006); Cristea and Nguyen (2016); Gumpert et al. (2016); Guvenen et al. (2017); and Davies et al. (2018).

${ }^{5}$ The project is called "Base Erosion and Profit Shifting." Further details can be found at https:// www.oecd.org/g20/topics/taxation/beps.htm, accessed on 17 March 2017.

${ }^{6}$ See http://www.oecd.org/ctp/oecd-presents-outputs-of-oecd-g20-beps-project-for-discussion-at-g20finance-ministers-meeting.htm, accessed on 17 March 2017.

${ }^{7}$ The CUP method is applied to tangible assets. The corresponding method for intangible assets is called the comparable uncontrolled transaction (CUT) method. There are other methods such as cost-plus method, resale price method, and profit split method. See OECD (2017, ch.2) for details.

${ }^{8}$ The uncontrolled transaction includes both a transaction of an MNE with an independent firm ("internal comparables") and a transaction between other independent firms ("external comparables"). Our framework captures the internal comparable transaction.
} 
an equally reliable manner (OECD, 2017, para. 2.3). The second aim of this paper is to investigate the impact of the ALP on MNEs' tax avoidance and production location choice.

We present a simple two-country model with a vertically-related MNE and a local downstream firm. The MNE has a headquarters in the parent country and a downstream affiliate in the host country. It locates an upstream affiliate in either the parent or the host, which provides inputs to both the two downstream firms in the host. The headquarters makes exogenous profits from different business in the parent. Corporate tax rates are exogenous and the parent's tax rate is assumed to be higher than the host's.

We analyze the location pattern of upstream production under the cases with and without the ALP. If the ALP is imposed, the upstream affiliate must set equal prices to the two downstream firms. ${ }^{9}$ We show that without the ALP, the MNE may locate an upstream affiliate in the high-tax parent country. With the ALP, however, the MNE simply locates it in the low-tax host country. There exist tax rates for which the imposition of the ALP changes the location pattern. This location change leads to smaller tax revenues in the host country, but greater revenues globally.

At first glance, it seems surprising that the upstream affiliate may be located in the hightax country. The key is that the transfer price can be used as a profit shifting device if the upstream and downstream affiliates are separately located. The upstream affiliate located in

\footnotetext{
${ }^{9}$ In our setting, the arm's length price is the price that the upstream affiliate charged to the local downstream firm. As MNEs are usually not price takers, the AL price in an internal comparable transaction is more or less an MNEs' choice variable and thus is subject to manipulation (Cristea and Nguyen (2016)). Although tax authorities recognize this possibility of manipulation (see e.g., IRS§1.4821(d)(4)(iii)), they have to refer to internal comparable transactions in some cases due to limited information available. One recent example of such case is the transfer pricing case of Medtronic, a medical device company based in the US, v. the Internal Revenue Service (IRS) (see for details Global Tax Alert (News from Transfer Pricing), 21 June 2016: http://www.ey.com/gl/en/services/tax/international-tax/ alert--us-tax-court-imposes-a-proper-arms-length-allocation-method-for-transfer-pricing, accessed on 2 June 2018). Medtronic US gave license to its Puerto Rican affiliate for production. The affiliate purchased components from Medtronic US, manufactured finished medical devices, and sold them to the Puerto Rican market. Whereas the IRS accused Medtronic US of profit shifting for the years at issue, 2005-06, Medtronic US argued that the royalty rates charged to the Puerto Rican affiliate, which are a sort of transfer price of inputs, were the AL royalty rates in light of the CUT method. The AL royalty rates calculated by Medtronic US came from several internal comparable transactions, including a license agreement between Medtronic US and Siemens (German conglomerate company). In 2016, the US Tax Court accepted the royalty rates proposed by Medtronic US with small adjustments. See Avi-Yonah (2007) for other applications of the CUP/CUT method.
} 
the high-tax parent may set the transfer price low so as to shift the headquarters' exogenous profits to the low-tax host. The larger international tax difference gives more room for profit shifting, likely leading to geographical separation of affiliates. The introduction of the ALP limits the ability to manipulate the transfer price, so that the MNE simply prefers to locate its upstream affiliate in the low-tax host.

It is not surprising that the imposition of the ALP removes the opportunity of profit shifting and thus increases global tax revenues. However, even though the ALP encourages the co-location of affiliates in the host country, the host's tax revenues decrease. The ALP makes the transfer price of inputs higher, leading the downstream affiliate to produce less. The reduction in the downstream affiliate's profits is so huge that the host country earns less tax revenues. Our result indicates that the ALP is certainly an effective measure against worldwide profit shifting, but may cause a conflict of interest between countries.

Our contribution is to examine the location choice of MNEs using transfer pricing, to which most of the studies in the literature have provided limited attention. Their main interest is in how transfer prices are affected by international differences in, e.g., corporate tax rates, tax systems, and trade barriers. ${ }^{10}$ Nielsen et al. (2003) examine how different corporate tax systems, separate accounting and formula apportionment, affect transfer prices differently. Kind et al. (2005) ask the same question in a tax competition framework and also look at the impact of a reduction in trade barriers. However, the production location choice of MNEs is outside the scope of these papers.

There are a few papers that address the choice of organization structure of MNEs with profit shifting motives. Nielsen et al. (2008) analyze the impact of different decision structures on transfer prices; i.e., the decision on production is made either by the headquarters of MNEs (centralization) or by the local affiliate (decentralization). Unlike our model, their model fixes the location of affiliates. Using the property-rights approach, Bauer and Langenmayr (2013)

\footnotetext{
${ }^{10}$ Earlier contributions include Copithorne (1971); Horst (1971); Samuelson (1982); and Kant (1988). In addition to the profit-shifting motive of transfer pricing mentioned in the text, studies such as Elitzur and Mintz (1996); Schjelderup and Sørgard (1997); and Zhao (2000) point out a strategic motive. The strategic motive comes from MNEs' incentive to make their downstream affiliates competitive against rival firms. See Section 4.4. for more on this point.
} 
and Egger and Seidel (2013) investigate the organization decision on whether to integrate local suppliers or import inputs from independent foreign suppliers. Keuschnigg and Devereux (2013) ask the same question in a model with financial frictions. While they focus on sourcing decisions across the boundaries of MNEs ("make or buy" inputs), we emphasize production location decisions within the boundaries of MNEs. ${ }^{11}$ Closer to the interests of our study, Yao (2013) analyzes the impact of the ALP on MNEs' location choice in a spatial competition model à la Hotelling. In his model, MNEs choose where to locate within a host country, that is, they choose a point on the "linear-city," whereas in our model an MNE chooses whether to locate in a host or parent country. ${ }^{12}$

Although the location choice of internationally-mobile firms is at the core of the literature on tax competition, ${ }^{13}$ the role of the transfer pricing and/or the ALP has not been addressed there. Haufler and Wooton (1999) consider tax competition between potential host countries for a single MNE (or its affiliate) without profit shifting motives. ${ }^{14}$ Based on their framework, Ma and Raimondos (2015) allow the MNE to use transfer pricing and examine the effect of the market size of potential host countries. They simplify the vertical structure within the MNE, and are thus unable to analyze the impact of the ALP. In contrast, we take corporate taxes as given, and describe the vertical structure more precisely to address the ALP issue.

The rest of the paper is organized as follows. Section 2 describes the setup of the model. The main analysis is presented in Sections 3 and 4 where the equilibrium outcomes in the benchmark (no-ALP) and the ALP cases are derived. Section 5 analyzes the impact of the ALP on tax revenues. Section 6 concludes the paper.

\footnotetext{
${ }^{11}$ In a related context, Choi et al. (2018) find a possibility of dual sourcing where an MNE buys inputs from both independent suppliers and related subsidiaries.

${ }^{12}$ The role of the ALP on transfer prices is also studied by Gresik and Osmundsen (2008); Bauer and Langenmayr (2013); Choe and Matsushima (2013); and Keuschnigg and Devereux (2013). However, they do not consider the location choice of MNEs.

${ }^{13}$ See Keen and Konrad (2013) for a comprehensive survey.

${ }^{14}$ For subsequent development in the literature on bidding for a firm, see, e.g., Bjorvatn and Eckel (2006); Haufler and Wooton (2006); Ferrett and Wooton (2010); and Furusawa et al. (2015).
} 


\section{Basic Setting}

The economy consists of two countries, a host and a parent, with two vertically-linked industries, an upstream industry (intermediate input) and a downstream industry (final good). Our focus is on the host country, where the consumption and production of final goods take place. The headquarters of the MNE is located in the parent country and makes exogenous profits $\bar{\pi}$. In the host country, there are a downstream affiliate of the MNE and a local downstream firm. The two firms produce totally differentiated goods.

The MNE locates an upstream affiliate in either the parent country with tax rate $T$ or the host country with tax rate $t(<T)$. If the upstream affiliate is established in the host together with the downstream affiliate, termed as a co-location scheme, it produces and sells inputs to both the related and unrelated downstream firms. The price for the related affiliate is called an internal price and the price for the independent local firm is called an arm's length price. By contrast, if the upstream affiliate is established in the parent separate from the downstream affiliate, termed as a separate-location scheme, it produces in the parent and exports to the two downstream firms. The internal price under this scheme can also be called a transfer price due to the cross-border transactions. The two schemes are illustrated in Fig. 1. 
(a)

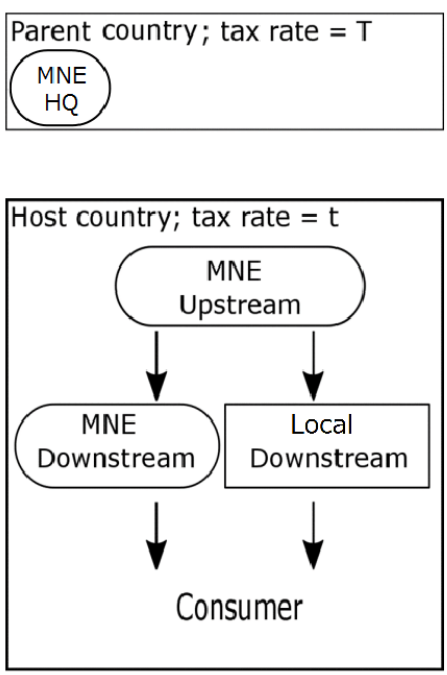

(b)

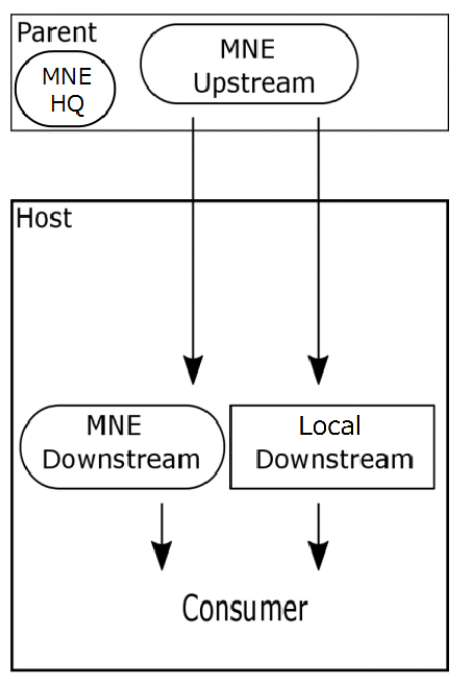

Fig. 1. Model structure: (a) co-location scheme; (b) separate-location scheme

The timing of the game is as follows. First, the MNE chooses the location of upstream production (Fig. 1.(a) or (b)). Second, it sets input prices to maximize the total posttax profit, which is the sum of the post-tax profits of the upstream and the downstream affiliates. Third, the downstream affiliate and the local firm choose outputs to maximize their own profits. ${ }^{15}$ We proceed by analyzing in turn the case where the MNE is free from the arm's length principle (ALP) and the case where it obeys the ALP.

\section{Benchmark Case}

We first consider the case where the ALP is not imposed: the upstream affiliate can sell to the related downstream affiliate and the independent firm at different prices. The equilibrium outcomes are derived in both the co-location and the separate-location schemes. Comparing the equilibrium profits under the two schemes, we analyze in which country the MNE locates

\footnotetext{
${ }^{15}$ We consider a decentralized decision structure where the MNE leaves quantity choice to the downstream affiliate.
} 
the upstream affiliate, given the tax rates of the host and the parent countries.

\subsection{Co-location Scheme}

Given the location of upstream production, the MNE first chooses input prices and then the two downstream firms source the inputs to produce final goods. We solve the problem backward.

The two downstream firms choose quantities to maximize their own pre-tax profits. Let $\pi$ and $\pi_{*}$ be respectively the pre-tax profits of the downstream affiliate and the local firm; the maximization problems are formulated as

$$
\begin{aligned}
\max _{q} \pi & =(p-g) q, \\
\max _{q_{*}} & \pi_{*}=\left(p_{*}-g_{*}\right) q_{*}, \\
\text { where } & p=1-q, \\
p_{*} & =1-q_{*} .
\end{aligned}
$$

$p\left(p_{*}\right)$ is the final good's price of the downstream affiliate (the local firm) and $q\left(q_{*}\right)$ is the quantity produced by the downstream affiliate (the local firm). The downstream firms use linear production technology, resulting in a one-to-one transformation from intermediate to final goods. $g$ is the price of the intermediate inputs for the downstream affiliate, called the internal price, and $g_{*}$ is the price for the local firm, called the arm's length price. Solving the maximization problems gives

$$
\begin{aligned}
q & =\frac{1-g}{2}, \\
q_{*} & =\frac{1-g_{*}}{2} .
\end{aligned}
$$

Taking into account these demand schedules, the MNE sets input prices for the two downstream firms. Letting $\pi_{u}$ be the pre-tax profits of the upstream affiliate and $\Pi$ be the total 
post-tax profit of the MNE, the MNE faces the following problem:

$$
\begin{aligned}
\max _{g, g_{*}} \Pi & =(1-T) \bar{\pi}+(1-t)\left(\pi_{u}+\pi\right) \\
& =(1-T) \bar{\pi}+(1-t)\left[(g-c) q+\left(g_{*}-c\right) q_{*}+(p-g) q\right],
\end{aligned}
$$

where $T$ and $t$ are respectively the parent's corporate tax rate and the host's. It is assumed that $t<T$ throughout the analysis. ${ }^{16} c \in[0,1)$ is the constant marginal cost of the upstream production. $\bar{\pi}$ is constant profits earned (from different business) in the parent market. ${ }^{17}$

Deriving the two first-order conditions (FOCs) from the MNE's problem $(d \Pi / d g=0$; $\left.d \Pi / d g_{*}=0\right)$ and solving the system of equations for $\left(g, g_{*}\right)$, we obtain

$$
\begin{aligned}
& g=c, \\
& g_{*}=\frac{1+c}{2},
\end{aligned}
$$

where the second-order conditions (SOCs) trivially hold. The equilibrium input prices are independent of tax rates because both the upstream and downstream firms co-locate in the host country and face the same tax rate. The MNE exercises monopoly power against the local firm by setting $g_{*}$ greater than the marginal cost $c$. By contrast, it adopts marginal cost pricing for the downstream affiliate to avoid losses from inefficient markups.

Using equilibrium choices, the total post-tax profit $\Pi$ is re-expressed as

$$
\Pi=(1-T) \bar{\pi}+\frac{3(1-t)(1-c)^{2}}{8}
$$

\footnotetext{
${ }^{16}$ If $t \geq T$, the upstream affiliate is always located in the low-tax parent country (separate location) in both the benchmark and ALP cases. Thus, our focus is on the range of $t<T$, where the imposition of the ALP may change the location pattern.

${ }^{17}$ It is common in the literature to assume exogenous profits or profits independent of transfer price (Schjelderup and Sørgard, 1997; Nielsen et al., 2003, 2008; Haufler and Mardan, 2014). In these studies, the tax-manipulation effect, which we will define shortly, is so strong that the price-cost margin (and thus profits) can be negative as in our analysis. To isolate the tax-manipulation effect as clearly as possible, we follow the convention of the literature. In Appendix 8, we endogneize it by introducing a local downstream firm in the parent country.
} 


\subsection{Separate-location Scheme}

In the separate-location scheme, where the upstream affiliate is located in the parent country, the two downstream firms behave similarly to the co-location scheme. Suppose the superscript $S$ denotes variables in the separate-location scheme. From Eqs. (1) and (2), the outputs of final goods can be written as

$$
\begin{aligned}
q^{S} & =\frac{1-g^{S}}{2}, \\
q_{*}^{S} & =\frac{1-g_{*}^{S}}{2},
\end{aligned}
$$

where $g$ and $g_{*}$ have been replaced with $g^{S}$ and $g_{*}^{S}$ in Eqs. (1) and (2), respectively.

Given these demand schedules, the MNE chooses input prices to maximize the following total post-tax profit:

$$
\begin{aligned}
\max _{g^{S}, g_{*}^{S}} \Pi^{S} & =(1-T)\left(\bar{\pi}+\pi_{u}^{S}\right)+(1-t) \pi^{S} \\
& =(1-T)\left[\bar{\pi}+\left(g^{S}-c\right) q^{S}+\left(g_{*}^{S}-c\right) q_{*}^{S}\right]+(1-t)\left(p^{S}-g^{S}\right) q^{S} .
\end{aligned}
$$

Our focus is on a certain range of tax rates where the maximization problem has a unique interior solution:

$$
\begin{aligned}
& t>\underline{t} \equiv \max \left\{0, t^{a}, t^{b}\right\}, \\
& \text { where } t^{a} \equiv 2 T-1, \\
& \qquad t^{b} \equiv[(3+c) T-(1+c)] / 2 .
\end{aligned}
$$

If $t$ and $T$ satisfy (A1): $t>\underline{t}$, equilibrium outputs and prices of intermediate and final goods are positive, and the SOCs hold in all cases of the following analysis. ${ }^{18}$ The regularity

\footnotetext{
${ }^{18}$ More precisely, $q^{S}>0$ requires $t>t^{a}$, while $p^{S}>0$ does $t>t^{b}$.
} 
condition (A1) is assumed throughout the analysis.

The equilibrium input prices are given by

$$
\begin{aligned}
& g^{S}=c+\underbrace{\frac{(1-c)(t-T)}{t-2 T+1}}_{\text {Tax-manipulation effect }}, \\
& g_{*}^{S}=\frac{1+c}{2},
\end{aligned}
$$

where the SOCs are satisfied and $t-2 T+1>0$ holds under (A1). The second term of $g^{S}$ involves the tax difference, which is termed as a tax-manipulation effect of transfer price. Its sign depends on the tax difference. If both countries had the same tax rate $(t=T)$, it would hold that $g^{S}=c(=g)$, meaning no room for tax manipulation. Under our assumption that $t<T$, the second term of $g^{S}$ is negative and $g^{S}<c$ holds. By making upstream profit negative, the MNE shifts exogenous profits from the high-tax parent to the low-tax host country. A larger tax difference $(t<<T)$ brings more room for profit shifting and thus lowers $g^{S}$ more. ${ }^{19}$

It is also noted that the arm's length price $g_{*}^{S}$ is equal to the one in the co-location scheme, and does not depend on tax rates. This is again because $g_{*}^{S}$ is used solely for exploiting market power against the local firm.

The total post-tax profit evaluated at the equilibrium choices is given by

$$
\Pi^{S}=(1-T)\left[\bar{\pi}+\frac{(1-c)^{2}(t-4 T+3)}{8(t-2 T+1)}\right]
$$

where the second term in the square bracket is positive under (A1): $t>\underline{t}$.

\footnotetext{
${ }^{19}$ Clausing (2003) empirically supports this result: she finds that MNEs in the U.S. tend to set lower export prices, as tax rates in the trading partners are lower.
} 


\subsection{Location Choice}

Comparing the total post-tax profits in the two schemes, the MNE chooses a location for upstream production. From Eqs. (5) and (8), the profit difference can be calculated as

$$
\Pi-\Pi^{S}=\frac{(1-c)^{2}(3 t-4 T+1)(T-t)}{8(t-2 T+1)},
$$

where $t-2 T+1>0$ holds under (A1). As the denominator is positive, the sign of the difference is determined by the numerator.

It can be seen that $\Pi-\Pi^{S}=0$ holds at $t \in\left\{t^{*}, T\right\}$, where $t^{*}$ is defined by

$$
t^{*} \equiv(4 T-1) / 3(<T) .
$$

$t^{*}$ is positive if the parent's tax rate is sufficiently high, i.e., $T>\bar{T} \equiv 1 / 4$.

The profits under the two schemes are illustrated in Fig. $2 .{ }^{20}$ If the parent's tax rate is low $\left(T \leq \bar{T}\right.$ : Fig. 2.(b)), $t^{*}$ becomes negative and $\Pi-\Pi^{S}>0$ holds for $t<T$. The MNE always co-locates the upstream affiliate with the downstream affiliate in the host country.

If the parent's tax rate is high ( $T>\bar{T}$ : Fig. 2.(a)), the location choice is more complex. $\Pi-\Pi^{S}>0$ holds if $t$ is close to $T$ (i.e., $t \in\left(t^{*}, T\right)$ ), while $\Pi-\Pi^{S} \leq 0$ holds if $t$ is far below $T$ (i.e., $\left.t \in\left(\underline{t}=0, t^{*}\right]\right)$. The MNE chooses the co-location scheme, if the two countries have similar tax rates. Otherwise, it prefers the separate-location scheme.

\footnotetext{
${ }^{20}$ These figures are derived using the following parameter values: $c=0.3 ; \quad \bar{\pi}=3 ;$ (a) $T=0.35 ;$ (b) $T=0.2$. In this numerical example, $\underline{t}=0$ holds. We note that the qualitative results stated in Proposition 1 do not depend on these particular parameter values.
} 


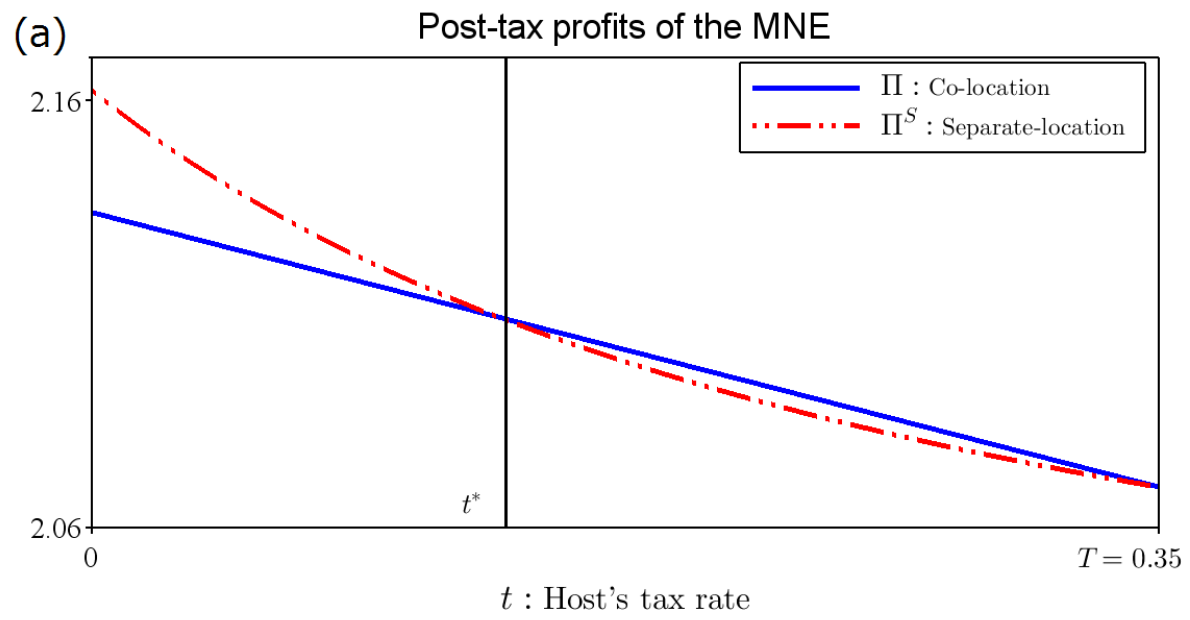

(b)

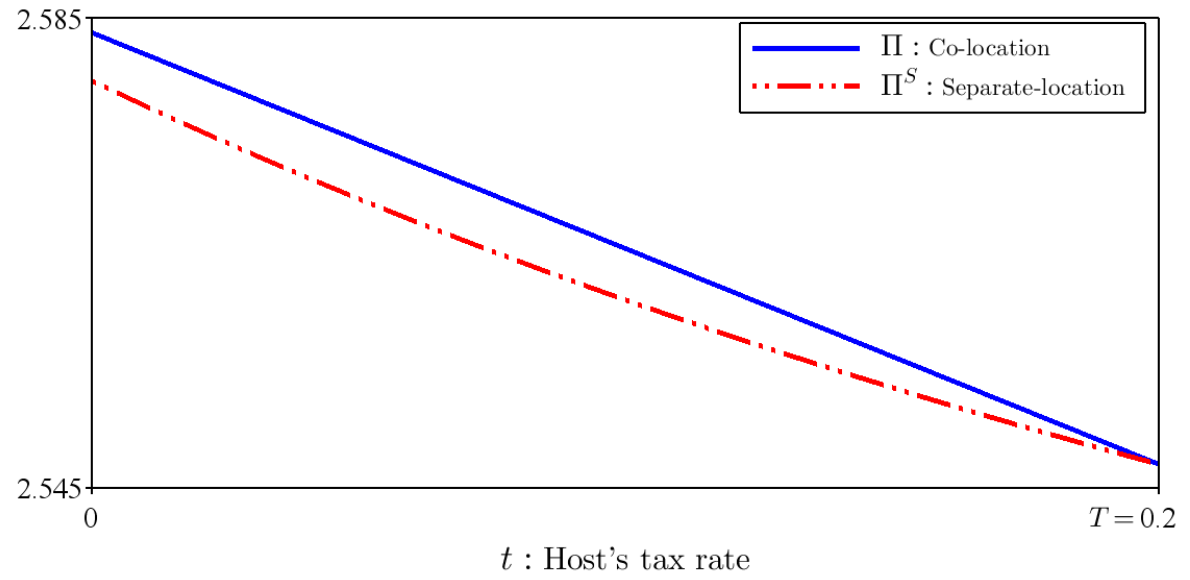

Fig. 2. Production location choice in the benchmark case: (a) high $T$ and (b) low $T$

If the two countries had equal tax rates, the tax manipulation effect would disappear so that the location choice would not matter, i.e., $\Pi=\Pi^{S}$ at $t=T$. Consider then a marginal decrease in the host's tax rate from $t=T$. The MNE naturally benefits from this reduction, but the degree of benefit varies from scheme to scheme. Indeed, we can confirm

$$
-\left.\frac{d \Pi}{d t}\right|_{t=T}>-\left.\frac{d \Pi^{S}}{d t}\right|_{t=T} .
$$

The marginal profit in the co-location scheme is higher than that in the separate-location scheme. Having an upstream affiliate in the parent is beneficial to the MNE trying to 
manipulate tax payments, but it comes at a cost of the higher tax rate in the parent. Under small international tax differences, there is little room for manipulating tax payments. Thus, the low-tax host becomes more profitable for upstream production than the high-tax parent.

Under fairly large tax differences, however, this is not necessarily the case. Let us assume $T>\bar{T}$ and look at the marginal effects of taxes on the total post-tax profit at $t=t^{*}>0$, where $\Pi=\Pi^{S}$ holds. We can confirm

$$
-\left.\frac{d \Pi}{d t}\right|_{t=t^{*}}<-\left.\frac{d \Pi^{S}}{d t}\right|_{t=t^{*}} .
$$

In contrast to the previous case of $t=T$, a reduction in $t$ increases total post-tax profit in the separate-location scheme more than in the co-location scheme. A larger tax difference strengthens the tax-manipulation effect and thus allows more profit shifting. To exploit the profit-shifting opportunity, the upstream affiliate is separately located from the downstream affiliate for $t \leq t^{*}$.

These results are summarized as follows.

Proposition 1 (No-ALP case). Suppose the MNE can set different input prices for its downstream affiliate and the local firm, and assume $t<T$ and the regularity condition (A1): $t>\underline{t}$. Two cases may arise:

(i) Suppose the parent country's tax rate is sufficiently high $(T>\bar{T})$. If the host country's tax rate is not low enough $\left(t \in\left(t^{*}, T\right)\right)$, the $M N E$ locates an upstream affiliate in the low-tax host country ("co-location"). On the other hand, if it is low enough $\left(t \in\left(\underline{t}, t^{*}\right]\right)$, the upstream affiliate is located in the high-tax parent country ("separate location").

(ii) Suppose the parent country's tax rate is not sufficiently high $(T \leq \bar{T})$. For any host's tax rate $(t \in(\underline{t}, T))$, the $M N E$ always locates an upstream affiliate in the low-tax host country ("co-location"). 


\section{Arm's Length Principle (ALP) Case}

Let us turn to the case where the MNE follows the ALP. It now sets equal prices to both the downstream affiliate and independent local firm. ${ }^{21}$

\subsection{Co-location Scheme}

We first solve the third stage game, where the downstream firms choose quantities, and then solve the second stage game, where the MNE chooses input prices. Maximization problems facing the downstream firms are exactly the same as in the benchmark (no-ALP) case, except that both the affiliate and the local firm source inputs at the same price, $\tilde{g}$, where the tilde $(\sim)$ represents the variable in the ALP case. Replacing $g$ and $g_{*}$ with $\tilde{g}$ in Eqs. (1) and (2) gives

$$
\tilde{q}=\tilde{q}_{*}=\frac{1-\tilde{g}}{2}
$$

Noting the MNE is unable to discriminate prices, its maximization problem is formulated as

$$
\begin{aligned}
\max _{\tilde{g}} \widetilde{\Pi} & =(1-T) \bar{\pi}+(1-t)\left(\tilde{\pi}_{u}+\tilde{\pi}\right) \\
& =(1-T) \bar{\pi}+(1-t)[2(\tilde{g}-c) \tilde{q}+(\tilde{p}-\tilde{g}) \tilde{q}] .
\end{aligned}
$$

The profits from selling inputs, $2(\tilde{g}-c) \tilde{q}$, are doubled because prices and quantities for the two downstream firms are the same.

\footnotetext{
${ }^{21}$ We assume that the ALP applies to both cross-border transactions (i.e., separate location) and domestic transactions (i.e., co-location). Article Nine and the OECD guidelines are fully or partly applicable to domestic transfer pricing in some member countries of the OECD such as the U.K., Norway and Canada (Wittendorff, 2012).
} 
From the FOC with respect to $\tilde{g}$, the following optimal input price is obtained:

$$
\tilde{g}=\frac{1+2 c}{3},
$$

where the SOC trivially holds. Comparing this with the input prices under the co-location

scheme in the benchmark case, $g$ and $g_{*}$ defined in Eqs. (3) and (4), we find $g<\tilde{g}<g_{*}$. In the benchmark case, the MNE exercises market power against the local firm and sets the arm's length price higher than the marginal cost $\left(g_{*}>c\right)$. For the downstream affiliate, the MNE sets the internal price to the marginal cost $(g=c)$ so as to avoid inefficient markups between affiliates. The ALP, however, does not allow for price discrimination so that the unique price reflects the two opposing motives. Therefore, the input price in the ALP case falls between the two prices in the benchmark case.

The total post-tax profit in equilibrium is given by

$$
\widetilde{\Pi}=(1-T) \bar{\pi}+\frac{(1-t)(1-c)^{2}}{3} .
$$

\subsection{Separate-location Scheme}

The quantities that the downstream firms choose are the same as in the co-location scheme:

$$
\tilde{q}^{S}=\tilde{q}_{*}^{S}=\frac{1-\tilde{g}^{S}}{2}
$$

where the superscript $S$ represents the separate-location scheme as before. Given these demand schedules, the MNE chooses an input price to maximize the total post-tax profit:

$$
\max _{\tilde{g}^{S}} \widetilde{\Pi}^{S}=(1-T)\left[\bar{\pi}+2\left(\tilde{g}^{S}-c\right) \tilde{q}^{S}\right]+(1-t)\left(\tilde{p}^{S}-\tilde{g}^{S}\right) \tilde{q}^{S}
$$


Solving the FOC yields the equilibrium input price:

$$
\tilde{g}^{S}=\frac{1+2 c}{3}+\underbrace{\frac{2(1-c)(t-T)}{3(t-4 T+3)}}_{\text {Tax-manipulation effect }}
$$

where the SOC is satisfied and $t-4 T+3>0$ holds under the regularity condition (A1): $t>\underline{t}$. The second term of $\tilde{g}^{S}$ captures the tax-manipulation effect as seen in $g^{S}$ defined in Eq. (6). Its sign depends only on the tax difference. The above input price can be reduced to the one under the co-location scheme $\left(\tilde{g}^{S}=\tilde{g}\right)$ at $t=T$. For $t<T$, the second term becomes negative, implying that the MNE reduces the input price to bring more profits to the downstream affiliate in the low-tax host country. Comparing $\tilde{g}^{S}$ with $g^{S}$ reveals that the tax-manipulation effect is smaller in $\tilde{g}^{S}$ than in $g^{S} \cdot{ }^{22}$ The input price is no longer an effective device for shifting profits. As in the co-location scheme, the input price in the ALP case falls between the transfer price and the arm's length price in the benchmark case, i.e., $g^{S}<\tilde{g}^{S}<g_{*}^{S}$.

The equilibrium total post-tax profit is calculated as

$$
\widetilde{\Pi}^{S}=(1-T)\left[\bar{\pi}+\frac{(1-c)^{2}(1-T)}{t-4 T+3}\right]
$$

${ }^{22}$ To see this formally, we calculate the difference between the coefficient of $t-T$ in $\tilde{g}^{S}$ and that in $g^{S}$ :

$$
\begin{aligned}
\frac{\partial \tilde{g}^{S}}{\partial(t-T)}-\frac{\partial g^{S}}{\partial(t-T)} & =\frac{2(1-c)}{3(t-4 T+3)}-\frac{1-c}{2(t-2 T+1)} \\
& =-\frac{(t-8 T+7)(1-c)}{12(t-4 T+3)(t-2 T+1)}<0 .
\end{aligned}
$$




\subsection{Location Choice}

From Eqs. (11) and (13), the profit difference is given by

$$
\widetilde{\Pi}-\widetilde{\Pi}^{S}=\frac{(1-c)^{2}(t-3 T+2)(T-t)}{3(t-4 T+3)},
$$

where $t-3 T+2>0$ and $t-4 T+3>0$ hold under $(\mathrm{A} 1)$. The profits under the two schemes are illustrated in Fig. 3. ${ }^{23}$ The sign of the profit difference depends only on $T-t$. Under our assumption that $t<T$, it holds that $\widetilde{\Pi}-\widetilde{\Pi}^{S} \geq 0$ and thus the MNE always prefers the co-location scheme. In contrast to the benchmark case, the separate-location scheme is never optimal even if $T$ is much higher than $t$. The input prices can neither be effectively used to exercise market power against the local firm, nor to shift profits, thereby reducing the benefit of choosing the separate-location scheme.

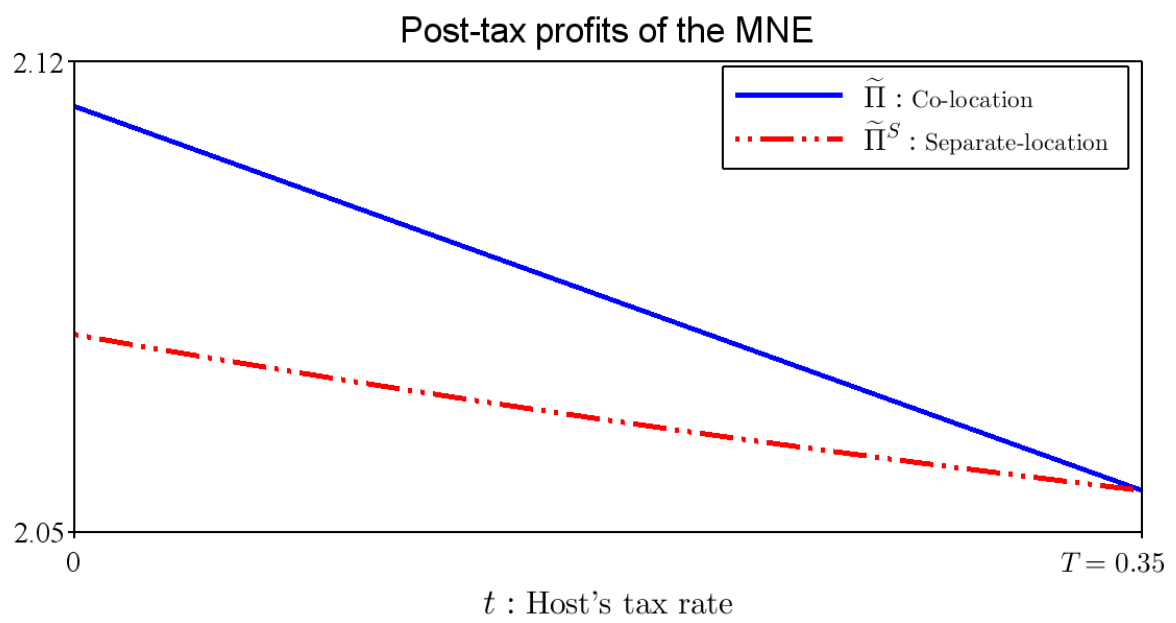

Fig. 3. Production location choice in the ALP case

Proposition 2 (ALP case). Suppose the MNE sets equal input prices for its downstream affiliate and the local firm, and assume $t \leq T$ and the regularity condition (A1): $t>\underline{t}$. For

\footnotetext{
${ }^{23}$ The parameter values are the same as those in Fig. $1(\mathrm{a}): c=0.3 ; \bar{\pi}=3 ; T=0.35$. We note that the qualitative results stated in Proposition 1 do not depend on these particular parameter values.
} 
any host's tax rate $(t \in(\underline{t}, T))$, the $M N E$ always locates an upstream affiliate in the low-tax host country ("co-location").

\subsection{Extensions and Robustness}

We have seen that the upstream affiliate may be located in the parent country (separate location) even if the parent's tax rate is higher than the host's (Proposition 1), and the imposition of the ALP may change the separate-location scheme to the co-location scheme (Proposition 2). One may wonder these results crucially depend on our simplified structure, where the intermediate inputs are supplied only by the upstream affiliate, and there is only one local firm in the downstream market. We briefly discuss the robustness of the results against three extensions: (i) imperfect substitutability between the two final goods, (ii) a local upstream firm, and (iii) many downstream firms.

Substitutability of the Final Goods. We allow for the two final goods to be substitutable. The transfer price has then a strategic effect as well as the tax-manipulation effect. As the strategic effect reduces the transfer price to make the downstream affiliate competitive, it works in the same direction as the tax-manipulation effect.

Let $b \in(0,1)$ denote the degree of substitutability of the goods. If $b$ is so high that competition in the downstream industry is tough, the MNE prevents the local firm from doing business by stopping selling inputs to it. Unless such input foreclosure occurs, we obtain the qualitatively same results as in Propositions 1 and 2. See our working paper (Kato and Okoshi, 2017) for details.

A Local Firm in the Upstream Industry. We add a local upstream firm in the host country. The upstream firm has the same marginal cost of $c$, supplies the same type of intermediate inputs as the upstream affiliate, and competes with it in prices. Bertrand competition with homogeneous products leads both the two upstream firms to set their prices equal to or lower 
than their marginal cost. The upstream firm cannot set its price lower than the marginal cost in order to earn non-negative profits. On the other hand, the upstream affiliate, if located in the parent country, can do so because its negative profits are compensated by the profits from different business $\bar{\pi}$. Thus, the MNE locates the upstream affiliate in the high-tax parent country as in Proposition 1.

In the ALP case, if the MNE were to set the input price lower than the marginal cost for the downstream affiliate, the price would also be applied to the local firm and thus lead to negative profits from it. The introduction of ALP makes the separate-location scheme less profitable than before and may change the location pattern as in Proposition 2. See Appendix 3 for details.

As we assume the two upstream firms produce the same type of inputs and have the same marginal cost, the arm's length price is uniquely identified. In practice, however, tax authorities may observe multiple uncontrolled comparable prices. The OECD guideline suggests that the arm's length price might be pinned down by statistical tools to narrow the price range such as the interquartile range or other percentiles (OECD, 2017, para. 3.57). In Appendix 7, we allow for the differentiation of inputs and analyze the case where the arm's length price takes a range of values.

Many Local Firms in the Downstream Industry. We allow for many local downstream firms, each of which produces a differentiated variety of products. A greater number of downstream firms yields more input sales. This implies that the downstream affiliate's profits relative to profits from local downstream firms become less important in the MNE's total profits. The MNE now lays less emphasis on the role of transfer prices and relies more on input sales from many local firms. Thus, it tends to prefer the co-location scheme simply for the low tax rate of the host country. However, if the number of downstream firms is not too large, Propositions 1 and 2 still hold. See Appendix 4 for details.

Furthermore, we extend our analysis to include (iv) extra costs of international trade, (v) extra costs of transfer pricing, and (vi) endogenous profits in the parent market. In these 
generalized settings, we obtain the qualitatively similar results to those of Propositions 1 and 2. The detailed analysis can be found in the Appendix.

\section{The Impact of the ALP on Tax Revenues}

It has been shown that the imposition of the ALP may change the location of upstream production from the parent to the host country. At first glance, this location change seems to enhance production in the host and bring larger tax revenues. However, this is not true.

It can be verified that for $t \in\left(\underline{t}, t^{*}\right)$, tax revenues under the separate-location scheme in the benchmark case, denoted by $T R_{H}$, are greater than those under the co-location scheme in the ALP case, denoted by $\widetilde{T R}_{H}:^{24}$

$$
\begin{aligned}
& \widetilde{T R}_{H}<T R_{H}, \\
& \text { where } \begin{aligned}
\widetilde{T R}_{H} & =t\left(\tilde{\pi}_{u}+\tilde{\pi}+\tilde{\pi}_{*}\right) \\
& =t \cdot 2(\tilde{p}-c) \tilde{q}, \\
T R_{H} & =t\left(\pi^{S}+\pi_{*}^{S}\right) \\
& =t\left[\left(p^{S}-g^{S}\right) q^{S}+\left(p_{*}^{S}-g_{*}^{S}\right) q_{*}^{S}\right],
\end{aligned}
\end{aligned}
$$

where it is noted that $\tilde{p}=\tilde{p}_{*}$ and $\tilde{q}=\tilde{q}_{*}$. The tax base in the benchmark case consists of the profits of the two downstream firms $\left(\pi^{S}+\pi_{*}^{S}\right)$, while in the ALP case the tax base includes the profits of the upstream affiliate $\left(\tilde{\pi}_{u}\right)$ as well as the two profits $\left(\tilde{\pi}+\tilde{\pi}_{*}\right)$. In the benchmark case, the transfer price is set lower than the true marginal cost. As a result, the downstream affiliate significantly expands and more goods are produced than in the ALP case, i.e., $q^{S}+q_{*}^{S}>2 \widetilde{q} .{ }^{25}$ In fact, the imposition of the ALP helps the local firm expand

\footnotetext{
${ }^{25}$ To see this formally, we have

$$
\begin{aligned}
& q^{S}+q_{*}^{S}-2 \tilde{q}=\left[2 \tilde{g}-\left(g^{S}+g_{*}^{S}\right)\right] / 2>0 \\
& \rightarrow t<(4 T+1) / 5 \equiv t^{q} .
\end{aligned}
$$
}

${ }^{24}$ For $t^{*}$ (defined in Eq. (9)) to be positive, we assume a sufficiently high $T$ such that $T>\bar{T}=1 / 4$. 
$\left(\tilde{q}_{*}=\tilde{q}>q_{*}^{S}\right)$, but discourages the production of the downstream affiliate $\left(\tilde{q}<q^{S}\right)$ and reduces the price-cost margin $\left(\tilde{p}-\tilde{g}<p^{S}-g^{S}\right) .{ }^{26}$ The contraction of host production combined with the narrower price-cost margin results in smaller tax revenues.

In contrast, it can be verified that in most cases, the location change induced by the ALP increases tax revenues globally:

$$
\begin{aligned}
& \widetilde{T R}_{W}>T R_{W} \\
& \text { where } \begin{aligned}
\widetilde{T R} & \\
& =T \bar{\pi}+t\left(\tilde{\pi}_{u}+\tilde{\pi}+\tilde{\pi}_{*}\right) \\
& =T \bar{\pi}+t \cdot 2[(\tilde{p}-\tilde{g})+(\tilde{g}-c)] \tilde{q}, \\
T R_{W} & =T\left(\bar{\pi}+\pi_{u}^{S}\right)+t\left(\pi^{S}+\pi_{*}^{S}\right) \\
& =T\left[\bar{\pi}+\left(g^{S}-c\right) q^{S}+\left(g_{*}^{S}-c\right) q_{*}^{S}\right]+t\left[\left(p^{S}-g^{S}\right) q^{S}+\left(p_{*}^{S}-g_{*}^{S}\right) q_{*}^{S}\right] .
\end{aligned}
\end{aligned}
$$

where tax revenues in the parent country are now included. In the benchmark case, the upstream affiliate sets the transfer price lower than the marginal cost $\left(g^{S}<c\right)$, and earns negative profits. The host country benefits from larger tax revenues at the expense of the parent country, but the benefit of the host does not exceed the loss of the parent. By imposing the ALP, the internal price is set higher than the marginal cost $(\tilde{g}>c)$, which brings positive profits to the upstream affiliate in the host country and leads to greater tax revenues globally.

These results are summarized as follows (see Appendix 2 for the proof).

Proposition 3 (Tax revenues). The imposition of the ALP changes the location of upstream production from the parent to the host country (from "separate location" to "co-

There exists $t$ satisfying the above inequality because it holds that $t^{a}<t^{q}<t^{*}$ and $t>\underline{t} \equiv \max \left\{0, t^{a}, t^{b}\right\}$ from (A1): $t>\underline{t}$.

${ }^{26}$ Noting that $g^{S}<g_{*}^{S}$ and $\tilde{g}>g_{*}^{S}$, we have

$$
\tilde{q}-q_{*}^{S}=\left(g_{*}^{S}-\tilde{g}\right) / 2>\left(g_{*}^{S}-g\right) / 2>0 .
$$

Combining this result with $q^{S}+q_{*}^{S}>2 \tilde{q}$ gives $\tilde{q}<q^{S}$. This also implies that the price-cost margin is smaller in the ALP case than in the benchmark case: $\tilde{q}=\tilde{p}-\tilde{g}<p^{S}-g^{S}=q^{S}$. 
location") if the international tax difference is large $\left(t \in\left(\underline{t}, t^{*}\right)\right)$. This location change decreases tax revenues in the host country, but increases those globally.

Considering the fact that countries adopt transfer pricing taxation to raise their tax revenues, the implementation of the ALP may give rise to an unintended consequence for countries with low corporate tax rates. Proposition 3 also suggests a conflict of interest in the ALP between low-tax and high-tax countries. ${ }^{27}$ In Appendix 9, we show that the results generally apply to social welfare. The ALP limits the use of transfer price and thereby leads to higher prices of final goods, which reduces consumer surplus in the host country. Thus the location change caused by the ALP would lower not only tax revenues, but also social welfare (consumer surplus and profits as well as tax revenues) in the host country. For a full analysis on welfare in a related model but without location choice, we refer independent works by Choi et al. (2018); and Ishikawa et al. (2017).

\section{Conclusion}

We have analyzed how corporate tax rates affect the production location choice of MNEs. One may think that internationally-mobile firms locate their production in low-tax countries, but this simple reasoning may not hold true for MNEs with multiple affiliates. MNEs attempt to reduce tax payments globally by manipulating transfer prices for intra-firm trade. Thus, they have an incentive to locate their upstream and downstream affiliates separately to exploit international tax differences. Contrary to the conventional wisdom, this paper shows that the upstream affiliate is likely to be located in the high-tax parent country, if its tax rate is much higher than that of the host country where the downstream affiliate is located.

With a view to preventing tax manipulation, the transfer pricing tax system requires MNEs to follow the ALP, where MNEs should not set different prices for related affiliates

\footnotetext{
${ }^{27}$ Similar results can be found in Yao (2013) in a different setting mentioned in the Introduction.
} 
and unrelated firms. We have also analyzed the impact of the ALP on the location choice of MNEs. With the ALP, MNEs are unable to fully utilize intra-firm transactions across borders for profit shifting. The ALP makes the transfer pricing strategy less effective, and thus may change the location pattern from a separate-location to a co-location of upstream and downstream affiliates. This location change seems to bring greater tax revenues to the country hosting the two affiliates, but we have demonstrated that this is not true. In contrast to a separate location, a co-location in the host country does not provide the scope of profit shifting from the parent country, which leads to the loss of tax base in the host. Owing to this, the host government may hesitate to implement the ALP strictly, although the ALP may increase global tax revenues.

We conclude by proposing possible extensions worth investigating. One extension is to allow taxes to be endogenously chosen by governments. In addition, one can think of many other policies to attract MNEs such as production and entry subsidies. Considering the importance of international tax planning, further analysis on different national tax systems is also needed such as the impact of a change from the separate accounting system to the formula apportionment system, or the role of the advance pricing agreement. These issues are left to future research. 


\section{Appendix}

\section{A.1. List of Key Variables}

\begin{tabular}{|c|c|c|}
\hline Benchmark & Co-location & Separate location \\
\hline Internal price of the input & $g$ & $g^{S}$ (transfer price) \\
Arm's length price of the input & $g_{*}$ & $g_{*}^{S}$ \\
Price of the affiliate's final good & $p$ & $p^{S}$ \\
Price of the local firm's final good & $p_{*}$ & $p_{*}^{S}$ \\
Quantity of the affiliate's final good & $q$ & $q^{S}$ \\
Quantity of the local firm's final good & $q_{*}$ & $q_{*}^{S}$ \\
Pre-tax profit of the upstream affiliate & $\pi_{u}$ & $\pi_{u}^{S}$ \\
Pre-tax profit of the downstream affiliate & $\pi$ & $\pi^{S}$ \\
Pre-tax profit of the local firm & $\pi_{*}$ & $\pi_{*}^{S}$ \\
Total post-tax profit of the MNE & $\Pi$ & $\Pi^{S}$ \\
\hline
\end{tabular}

\begin{tabular}{|c|c|c|}
\hline Arm's Length Principle (ALP) & Co-location & Separate location \\
\hline Arm's length price of the input & $\tilde{g}$ & $\tilde{g}^{S}$ \\
Price of the affiliate's final good & $\tilde{p}$ & $\tilde{p}^{S}$ \\
Price of the local firm's final good & $\tilde{p}_{*}$ & $\tilde{p}_{*}^{S}$ \\
Quantity of the affiliate's final good & $\tilde{q}$ & $\tilde{q}^{S}$ \\
Quantity of the local firm's final good & $\tilde{q}_{*}$ & $\tilde{q}_{*}^{S}$ \\
Pre-tax profi of the upstream affiliate & $\tilde{\pi}_{u}$ & $\tilde{\pi}_{u}^{S}$ \\
Pre-tax profit of the downstream affiliate & $\tilde{\pi}$ & $\tilde{\pi}^{S}$ \\
Pre-tax profit of the local firm & $\tilde{\pi}_{*}$ & $\tilde{\pi}_{*}^{S}$ \\
Total post-tax profit of the MNE & $\widetilde{\Pi}^{*}$ & $\widetilde{\Pi}^{S}$ \\
\hline
\end{tabular}

We note that (i) in the ALP case, the internal price is equal to the arm's length price, (ii) the downstream firms produce one unit of final goods using one unit of intermediate inputs, and (iii) the pre-tax profits from the parent country $\bar{\pi}$ are always constant.

\section{A.2. $\quad$ Proof of Proposition 3}

Tax Revenues in the Host Country. Assuming $T>\bar{T}=1 / 4$, we show that when $t \in\left(\underline{t}, t^{*}\right)$, tax revenues in the benchmark case, $T R_{H}$, are greater than those in the ALP case, $\widetilde{T R}_{H}$. It suffices to check the difference of taxable profits:

$$
\begin{aligned}
\widetilde{T R}_{H}-T R_{H} & =t\left[\tilde{\pi}_{u}+\tilde{\pi}+\tilde{\pi}_{*}-\left(\pi^{S}+\pi_{*}^{S}\right)\right]<0, \\
& \rightarrow \tilde{\pi}_{u}+\tilde{\pi}+\tilde{\pi}_{*}-\left(\pi^{S}+\pi_{*}^{S}\right) \equiv \Gamma<0 .
\end{aligned}
$$


If it is shown that (i) $\Gamma<0$ holds at $t=t^{*}$ and (ii) $\Gamma$ is increasing in $t$, we can conclude that $\Gamma$ is negative for $t \in\left(\underline{t}, t^{*}\right)$. First we check (i):

$$
\left.\Gamma\right|_{t=t^{*}}=-\frac{13(1-c)^{2}}{72}<0
$$

(ii) requires the following condition:

$$
\begin{aligned}
& \frac{d \Gamma}{d t}=-\frac{\partial\left(\pi^{S}+\pi_{*}^{S}\right)}{\partial g^{S}} \frac{d g^{S}}{d t}>0, \\
& \text { where } \frac{d g^{S}}{d t}=\frac{2(1-c)(1-T)}{t-2 T+1}>0,
\end{aligned}
$$

noting that profits earned in the host under the ALP, $\tilde{\pi}_{u}+\tilde{\pi}+\tilde{\pi}_{*}$, are independent of transfer price and thus of tax rates. We only need to check that profits in the host in the benchmark case, $\pi^{S}+\pi_{*}^{S}$, are decreasing in transfer price, $g^{S}$ :

$$
\begin{aligned}
\frac{\partial\left(\pi^{S}+\pi_{*}^{S}\right)}{\partial g^{S}} & =\frac{5 g^{S}-4}{8} \\
& <\frac{g_{*}^{S}-1}{2}<0,
\end{aligned}
$$

where we make use of $g^{S}<g_{*}^{S}$ and $g_{*}^{S}<1$. Both (i) and (ii) are proved to be true and thus we complete the proof.

Tax Revenues in the World. We first show $g^{S}<c$ for $t \in\left(\underline{t}, t^{*}\right)$ while assuming $T>\bar{T}=1 / 4$. $g^{S}<c$ requires the following condition:

$$
g^{S}-c=\frac{(1-c)(t-T)}{t-2 T+1}<0
$$

which obviously holds under our assumption.

We then show the following:

$$
\begin{aligned}
\widetilde{T R}_{W}-T R_{W} & =-T \pi_{u}^{S}+t\left[\tilde{\pi}_{u}+\tilde{\pi}+\tilde{\pi}_{*}-\left(\pi^{S}+\pi_{*}^{S}\right)\right] \\
& =-T \pi_{u}^{S}+t \Gamma \equiv \Delta>0
\end{aligned}
$$

where $T R_{W}$ and $\widetilde{T R}_{W}$ are world tax revenues in the benchmark and the ALP cases, respectively.

Analogous to the previous case, if it is shown that (i) $\Delta$ is positive at $t=t^{*}$ and (ii) $\Delta$ is decreasing in $t$, we can conclude that $\Delta>0$ holds for $t \in\left(\underline{t}, t^{*}\right)$. First we see (i):

$$
\left.\Delta\right|_{t=t^{*}}=\frac{(13-2 T)(1-c)^{2}}{216}>0 .
$$


To prove (ii), it suffices to show

$$
\begin{aligned}
\frac{d \Delta}{d t} & =-T \frac{d \pi_{u}^{S}}{d t}+\Gamma+t \frac{d \Gamma}{d t} \\
& <t\left(\frac{d \Gamma}{d t}-\frac{d \pi_{u}^{S}}{d t}\right)+\Gamma \\
& =t \frac{\partial\left(\pi^{S}+\pi_{*}^{S}-\pi_{u}^{S}\right)}{\partial g^{S}} \frac{d g^{S}}{d t}+\Gamma<0
\end{aligned}
$$

where from the first to the second line we make use of $t<t^{*}<T$. As we have seen $d g^{S} / d t>0$ and $\Gamma<0$, we only need to check

$$
\begin{aligned}
\frac{\partial\left(\pi^{S}+\pi_{*}^{S}-\pi_{u}^{S}\right)}{\partial g^{S}} & =-\frac{c+2-3 g^{S}}{2} \\
& <-\frac{c+2-3 c}{2} \\
& =-(1-c)<0
\end{aligned}
$$

noting that $g^{S}<c$ from the first to the second line. We complete the proof.

\section{A.3. A Local Firm in the Upstream Industry}

In the text, the upstream affiliate is the only supplier of inputs. One may wonder this setting is crucial for the results, but it is not the case. We see that the upstream affiliate may be located in the high-tax parent country ("separate location") in the benchmark case (Proposition 1) and the imposition of the ALP may change this location pattern (Proposition 2). We introduce a local upstream firm in the host country. The local upstream firm has the same marginal cost $c$ as the MNE's upstream affiliate and competes with the affiliate in a Bertrand fashion. The timing proceeds in the same manner as in the text. First, the MNE chooses a location for upstream production. Then the MNE and the local upstream firm set input prices. Finally the downstream affiliate and the local firm source the inputs and produce final goods.

As inputs produced by the two upstream firms are homogeneous, the downstream firms buy inputs from the lowest price supplier. Hence, the dominant strategy for the local upstream is to set its input price equal to the marginal cost $c$. Considering this strategy of the local upstream, the MNE sets input prices equal or lower than $c$. We need to modify the MNE's maximization problem so as to include inequality constraints on input prices.

Benchmark Case. Let us first look at the separate-location scheme. The maximization 
problem for the MNE is modified as $^{28}$

$$
\begin{aligned}
& \max _{g^{S}, g_{*}^{S}} \Pi^{S}=(1-T)\left[\bar{\pi}+\left(g^{S}-c\right) q^{S}+\left(g_{*}^{S}-c\right) q_{*}^{S}\right]+(1-t)\left(p^{S}-g^{S}\right) q^{S}, \\
& \text { s.t. } g^{S} \leq c, \quad g_{*}^{S} \leq c,
\end{aligned}
$$

where the final good's price $p^{S}$ and quantities $\left(q^{S}, q_{*}^{S}\right)$ are defined in Section 3 and we assume that the MNE upstream affiliate takes all the input demand if its prices are equal to the ones of the local upstream.

Letting $\lambda$ and $\mu$ be the Lagrange multipliers for the constraints of $g^{S} \leq c$ and $g_{*}^{S} \leq c$ respectively, we solve the above problem to get

$$
\begin{aligned}
& g^{S}=c+\frac{(1-c)(t-T)}{t-2 T+1}<c, \\
& \lambda=0, \\
& g_{*}^{S}=c, \\
& \mu=(1-c)(1-T) / 2>0,
\end{aligned}
$$

where we maintain the assumptions (A1): $t>\underline{t}$ and $t<T$. As the multipliers are all non-negative, the equilibrium prices satisfy the Kuhn-Tucker conditions for optimization. $g^{S}$ allows a similar interpretation to the one for the unconstrained optimal transfer price defined in Eq. (6). The first term is the base price equal to the arm's length price. The second term represents the tax-manipulation effect.

The associated post-tax profits are then given by

$$
\Pi^{S}=(1-T)\left[\bar{\pi}+\frac{(1-T)(1-c)^{2}}{4(t-2 T+1)}\right] .
$$

Under the co-location scheme in the benchmark case as discussed in Section 3, the MNE sets input prices higher than $c$ in the unconstrained maximization problem, i.e., $g>c$ and $g_{*}>c$. Hence, in the constrained problem here, it can be confirmed that the MNE sets input prices equal to $c$, i.e., $g=c$ and $g_{*}=c$, and obtains the following post-tax profits:

$$
\Pi=(1-T) \bar{\pi}+\frac{(1-t)(1-c)^{2}}{4} .
$$

As easily seen, $\Pi$ is smaller than $\Pi^{S}$ at $t \in(\underline{t}, T)$. In other words, the MNE's optimal choice is that the upstream affiliate is always located in the parent country (separate location). Even when considering the local upstream, our conclusion still holds; the upstream production may be located in the high-tax country for the tax-manipulation purpose.

\footnotetext{
${ }^{28}$ We do not distinguish the notation of variables between the unconstrained problem in the text and the constrained problem here.
} 
ALP Case. In the ALP case, the optimal input prices in the unconstrained problem discussed in Section 4 are never below the marginal cost $c$ under the two schemes, i.e., $\tilde{g}>c$ and $\tilde{g}^{S}>c$. By the same reasoning as before, it can be confirmed that the constrained problem gives the input prices equal to the marginal cost, i.e., $\tilde{g}=c$ and $\tilde{g}^{S}=c$. Hence, the associated profits are identical with the one under the co-location scheme in the benchmark case, i.e., $\widetilde{\Pi}=\widetilde{\Pi}^{S}=\Pi$ at $t \in(\underline{t}, T)$. Unlike the benchmark case, the tax-manipulation effect disappears and the two countries are indifferent as to the location choice. In this generalized setting, we still see that the imposition of the ALP may change the location pattern as argued in the text.

\section{A.4. Many Local Firms in the Downstream Industry}

As in A.3, we see here that our main conclusions are maintained in a more generalized setting than in the text. Consider $N$ local firms in the downstream industry. The local firms are assumed to be symmetric and have the same marginal cost $c$. If $N$ is set to be unity, all the following results reduce to the corresponding results in the text.

The demand functions for the downstream affiliate and the local firm $j$ are respectively given by

$$
\begin{aligned}
& p=1-q, \\
& p_{* j}=1-q_{* j} .
\end{aligned}
$$

The following procedure is the same as in the text and we solve the problem backward. Considering the above demand schedules, the downstream firms choose quantities to maximize their own profits:

$$
\begin{gathered}
q=\frac{1-g}{2}, \\
q_{* j}=\frac{1-g_{* j}}{2} .
\end{gathered}
$$

Benchmark Case. Given the optimal quantities the downstream firms choose, the MNE sets input prices to maximize its post-tax profits. In the co-location scheme, the equilibrium input prices are given by

$$
\begin{aligned}
& g=c, \\
& g_{*}=\frac{1+c}{2},
\end{aligned}
$$

where $g_{* j}=g_{*}$ holds for all $j$ and the SOCs trivially hold. 
The total post-tax profits in equilibrium are calculated as

$$
\Pi=(1-T) \bar{\pi}+\frac{(1-t)(1-c)^{2}(2+N)}{8} .
$$

The equilibrium input prices in the separate-location scheme are given by

$$
\begin{aligned}
& g^{S}=c+\frac{(1-c)(t-T)}{t-2 T+1}, \\
& g_{*}^{S}=\frac{1+c}{2},
\end{aligned}
$$

where $t-2 T+1>0$ and the SOCs hold under (A1): $t>\underline{t}$. Under $t<T$, the second term of $g^{S}$ is negative so that the tax-manipulation effect works in the same way as in Eq. (6).

The total post-tax profits in equilibrium are calculated as

$$
\Pi^{S}=(1-T)\left[\bar{\pi}+\frac{(1-c)^{2}\{N t-2(1+N) T+2+N\}}{8(t-2 T+1)}\right] .
$$

Taking difference between the post-tax profits in the two schemes gives

$$
\begin{aligned}
& \Pi-\Pi^{S}=\frac{\Theta^{\prime}(1-c)^{2}(T-t)}{16(t-2 T+1)}, \\
& \text { where } \Theta^{\prime} \equiv 2(2+N) t+4(1+N) T+2 N .
\end{aligned}
$$

The profit difference becomes zero at $t=T$ and $t=t^{\prime}$ where $t^{\prime}$ is the solution of $\Theta^{\prime}=0$. It can be confirmed that $t^{\prime}$ is in between $(\underline{t}, 1]$ if $N$ is not sufficiently large. ${ }^{29}$ In this case, we have $\Pi-\Pi^{S}<0$ for $t \in\left(\underline{t}, t^{\prime}\right)$ and $\Pi-\Pi^{S} \geq 0$ for $t \in\left[t^{\prime}, T\right)$. We can conclude that the MNE chooses the separate location if the tax difference is large as in Proposition 1.

ALP Case. Analogous to the benchmark case, the equilibrium input price under the colocation scheme becomes

$$
\tilde{g}=\frac{c+N+c N}{1+2 N}
$$

where the SOC trivially holds. It can be confirmed that $g<\tilde{g}<g_{*}$ holds as in the text. The total post-tax profits are given by

$$
\widetilde{\Pi}=(1-T) \bar{\pi}+\frac{(1-t)(1-c)^{2}(1+N)^{2}}{4(1+2 N)} .
$$

\footnotetext{
${ }^{29}$ It always holds that $t^{\prime}<T . t^{\prime}$ is decreasing in $N$ if $N$ is not sufficiently large, implying $t^{\prime}>\underline{t}$ for not sufficiently large $N$.
} 
Turning to the separate-location scheme, the equilibrium input price becomes

$$
\tilde{g}^{S}=\underbrace{\frac{c+N+c N}{1+2 N}}_{=\tilde{g}}+\frac{(1-c)(1+N)(t-T)}{(1+2 N)[t-2(1+N) T+1+2 N]} .
$$

We can check that as long as $N$ is not sufficiently large, $g^{S}<\tilde{g}<g_{*}$ holds as in the text.

The total post-tax profits under the separate-location scheme are given by

$$
\widetilde{\Pi}^{S}=(1-T)\left[\bar{\pi}+\frac{(1-T)(1-c)^{2}(1+N)^{2}}{4\{t-2(1+N) T+1+2 N\}}\right],
$$

where the SOC requires

$$
t-2(1+N) T+1+2 N>0
$$

The profit difference then becomes

$$
\widetilde{\Pi}-\widetilde{\Pi}^{S}=\frac{(T-t)(1-c)^{2}(1+N)^{2}[t-(1+2 N) T+2 N]}{4(1+2 N)[t-2(1+N) T+1+2 N]},
$$

which is positive as long as the SOC holds. This implies that in the ALP case the MNE always chooses the co-location scheme as in Proposition 2.

\section{A.5. Trade Costs}

We introduce here trade costs for inputs. If the upstream affiliate is located in the parent country, the downstream firms pay an extra unit trade cost $\tau>0$ when importing inputs (Kind et al., 2005). If it is located in the host country, trade costs play no role and the analysis is the same as in the text. Thus, we present only the results in the separate-location scheme in the following.

Benchmark Case. The maximization problems of the downstream firms are modified as

$$
\begin{aligned}
& \max _{q} \pi^{S}=\left(p^{S}-g^{S}-\tau\right) q^{S}, \\
& \max _{q_{*}} \pi_{*}^{S}=\left(p_{*}^{S}-g_{*}^{S}-\tau\right) q_{*}^{S} .
\end{aligned}
$$

Solving these gives

$$
\begin{aligned}
q^{S} & =\frac{1-g^{S}-\tau}{2}, \\
q_{*}^{S} & =\frac{1-g_{*}^{S}-\tau}{2} .
\end{aligned}
$$


The total post-tax profit of the MNE is also modified accordingly:

$$
\Pi^{S}=(1-T)\left[\bar{\pi}+\left(g^{S}-c\right) q^{S}+\left(g_{*}^{S}-c\right) q_{*}^{S}\right]+(1-t)\left(p^{S}-g^{S}-\tau\right) q^{S} .
$$

The equilibrium input prices to maximize it are given by

$$
\begin{aligned}
g^{S} & =c+\frac{(1-c-\tau)(t-T)}{t-2 T+1}, \\
g_{*}^{S} & =\frac{1+c-\tau}{2} .
\end{aligned}
$$

We impose an assumption of $\tau<1-c$ to ensure positive outputs. The equilibrium total post-tax profit is calculated as

$$
\Pi^{S}=(1-T)\left[\bar{\pi}+\frac{(1-c-\tau)^{2}(t-4 T+3)}{8(t-2 T+1)}\right] .
$$

Taking difference between the post-tax profits in the two schemes gives

$$
\begin{aligned}
& \Pi-\Pi^{S}=\frac{F(t)}{16(t-2 T+1)}, \\
& \text { where } \begin{array}{r}
F(t) \equiv-3(1-c)^{2} t^{2}+\left[\tau\{2(1-c)-\tau\}+(1-c)^{2}(7 T-1)\right] t \\
\quad+\tau[2(1-c)-\tau](1-T)(3-4 T)+T(4 T-1)(1-c)^{2} .
\end{array}
\end{aligned}
$$

We check (i) whether $F(t)=0$ has two real roots and (ii) whether at least either of them falls into $(\underline{t}, T)$.

$F(t)=0$ has two real roots if its determinant $D$ is positive:

$D(\tau) \equiv(1-T)^{2}\left[\tau^{4}-4(1-c) \tau^{3}-30(1-c)^{2} \tau^{2}-68(1-c)^{3} \tau+(1-c)^{4}\right]>0$, for $\tau \in[0,1-c)$.

We can verify this inequality by noting the following relations:

$$
\begin{aligned}
& D(\tau=0)=(1-T)^{2}(1-c)^{4}>0 \\
& D(\tau=1-c)=36(1-T)^{2}(1-c)^{4}>0 \\
& D^{\prime}(\tau)=-4(1-T)^{2}(1-c-\tau)\left[\tau^{2}-2(1-c) \tau-17(1-c)^{2}\right]>0
\end{aligned}
$$

Let $t_{1}$ and $t_{2}$ be respectively the smaller and the larger root of $F(t)=0$. From the facts that $F(t)$ has a negative coefficient of the quadratic term and that $\partial F(t ; \tau) / \partial \tau=$ $2(1-T)(1-c-\tau)(t-4 T+3)>0$ holds, we see $t_{1}$ is decreasing in $\tau$ while $t_{2}$ is increasing in $\tau$. At $\tau=0, t_{1}$ is reduced to $t^{*}=(4 T-1) / 3$ and $t_{2}$ to $T$.

If $T>3 / 4$ holds, $t_{1}$ lies in $(0, T)$ regardless of $\tau$ so that the separate-location scheme is chosen for $t \in\left(0, t_{1}\right)$. If $T \leq 3 / 4$ holds, $t_{1}$ may become negative at sufficiently high trade costs. The maximum level of trade costs that allows for the separate-location scheme is given 
by

$$
\bar{\tau}=(1-c) \sqrt{1-\frac{8 T^{2}-8 T+3}{(1-T)(3-4 T)}} .
$$

Even if $T \leq 3 / 4$, we observe the separate-location scheme for $t \in\left(0, t_{1}\right]$ as long as $\tau<\bar{\tau}$.

In sum, as in Proposition 1, assuming the parent's tax rate is high enough $(T>3 / 4)$, the MNE locates the upstream affiliate in the high-tax parent country if the host's tax rate is low enough $\left(t \in\left(\underline{t}, t_{1}\right]\right)$ and otherwise locates it in the low-tax host country. Higher trade costs reduce the range of tax rates where the separate-location scheme is chosen, i.e., $d t_{1} / d \tau<0$.

ALP Case. Analogously, the equilibrium input price to maximize the total post-tax profit is given by

$$
\tilde{g}^{S}=\frac{1+2 c-\tau}{3}+\frac{2(1-c-\tau)(t-T)}{3(t-4 T+3)} .
$$

The associated total post-tax profit becomes

$$
\widetilde{\Pi}^{S}=(1-T)\left[\bar{\pi}+\frac{(1-c-\tau)^{2}(1-T)}{t-4 T+3}\right] .
$$

The profit difference is given by

$$
\widetilde{\Pi}-\widetilde{\Pi}^{S}=\frac{(1-c)^{2}(t-3 T+2)(T-t)+3 \tau[2(1-c)-\tau](1-T)^{2}}{3(t-4 T+3)}>0,
$$

where we note that $\tau<1-c<2(1-c)$. This implies that with the ALP the MNE always chooses the co-location scheme as in Proposition 2.

\section{A.6. Costs of Transfer Pricing}

Some studies in the literature assume that MNEs are subject to an extra concealment cost of transfer pricing (e.g., Nielsen et al., 2003, 2008; Kind et al., 2005). We formulate here the concealment cost as a quadratic function of the difference between the transfer price and the arm's length price, i.e., $C\left(g, g_{*}\right)=\delta\left(g-g_{*}\right)^{2} / 2$ with $\delta \geq 0$. Following the above-mentioned studies, we assume that the upstream affiliate bears this cost. Thus, the concealment cost does not affect the optimal choices by the downstream firms, which are the same as those given in the text. 
Benchmark Case. In the co-location scheme, the total post-tax profit is modified as

$$
\begin{aligned}
& \Pi=(1-T) \bar{\pi}+(1-t)\left[(g-c) q+\left(g_{*}-c\right) q_{*}-C\left(g, g_{*}\right)+(p-g) q\right] \\
& \text { where } C\left(g, g_{*}\right)=\delta\left(g-g_{*}\right)^{2} / 2, \quad \delta \geq 0,
\end{aligned}
$$

noting that the optimal outputs $\left(q, q_{*}\right)$ chosen by the downstream firms are the same as those in the text: $q=(1-g) / 2 ; q_{*}=\left(1-g_{*}\right) / 2$. The equilibrium input prices to maximize it are given by

$$
\begin{aligned}
& g=\frac{\delta+c(1+2 \delta)}{1+3 \delta}, \\
& g_{*}=\frac{1+2 \delta+c(1+4 \delta)}{2(1+3 \delta)} .
\end{aligned}
$$

The equilibrium total post-tax profit then becomes

$$
\Pi=(1-T) \bar{\pi}+\frac{(1-t)(1-c)^{2}(3+8 \delta)}{8(1+3 \delta)} .
$$

In the separate-location scheme, we can analogously define the total post-tax profit and compute the equilibrium input prices as follows:

$$
\begin{aligned}
g^{S} & =c+\frac{(1-c)[t-T+\delta(t-2 T+1)]}{t-2 T+1+\delta(t-4 T+3)}, \\
g_{*}^{S} & =\frac{(t-2 T+1)(1+c+2 \delta)+4 c \delta(1-T)}{2[t-2 T+1+\delta(t-4 T+3)]} .
\end{aligned}
$$

The equilibrium total post-tax profit is calculated as

$$
\Pi^{S}=(1-T)\left[\bar{\pi}+\frac{(1-c)^{2}\{t-4 T+3+8 \delta(1-T)\}}{8\{t-2 T+1+\delta(t-4 T+3)\}}\right] .
$$

Taking difference between the post-tax profits in the two schemes gives

$$
\begin{aligned}
& \Pi-\Pi^{S}=\frac{G(t)(1-c)^{2}(T-t)}{8(1+3 \delta)[t-2 T+1+\delta(t-4 T+3)]}, \\
& \text { where } G(t) \equiv(1+\delta)(3+8 \delta) t-8(3 T-2) \delta^{2}-(20 T-9) \delta+1-4 T,
\end{aligned}
$$

noting that its sign only depends on $G(t) . G(t)=0$ holds at $t^{* *}$, which is defined by

$$
t^{* *}=\frac{4 T-1}{3}-\frac{8 \delta(2+5 \delta)(1-T)}{3(1+\delta)(3+8 \delta)} .
$$

Without the concealment cost, $t^{* *}$ is reduced to $t^{*}$ defined in Eq. (8). When $T>\bar{T}=1 / 4$ 
holds as in the text and $\delta$ is not too high, $t^{* *}$ becomes positive. ${ }^{30}$ In this case, as in Proposition 1 , we observe the separate-location scheme for $t \in\left(\underline{t}, t^{* *}\right]$ and the co-location scheme for $t \in\left(t^{* *}, T\right)$. The more difficult concealment is, the less likely we are to observe the separatelocation scheme, i.e., $d t^{* *} / d \delta<0$.

ALP Case. As the transfer price must be equal to the arm's length price, the concealment cost plays no role. The results in both schemes are the same as those in the text.

\section{A.7. $\quad$ Differentiated Inputs}

In the text, the downstream affiliate and the local firm purchase the same input from the upstream affiliate. We consider here the situation where the two downstream firms need a different type of inputs. The upstream affiliate produces the two different inputs using different technology. That is, the marginal cost of input for the downstream affiliate is $c \in[0,1)$, while that for the local firm is $c_{*} \in[0,1)$.

As the input for the downstream firm is not perfectly comparable to that for the local firm, tax authorities cannot require that the prices of the two inputs must be the same. Instead, they allow for a certain range of arm's length price. This arm's length range gives the MNE room for price differentiation even under the ALP. The partial comparability of the two inputs implies that they are produced using more or less the same technology. We thus assume the difference of marginal cost is not too large: $\left|c_{*}-c\right|<1-c$.

Benchmark Case.

In the co-location scheme, the total post-tax profit is

$$
\Pi=(1-T) \bar{\pi}+(1-t)\left[(g-c) q+\left(g_{*}-c_{*}\right) q_{*}+(p-g) q\right]
$$

where the optimal outputs $\left(q, q_{*}\right)$ chosen by the downstream firms are the same as those in the text: $q=(1-g) / 2 ; q_{*}=\left(1-g_{*}\right) / 2$. The equilibrium input prices to maximize it are

$$
\begin{aligned}
& g=c, \\
& g_{*}=\frac{1+c_{*}}{2},
\end{aligned}
$$

where we note $g<g_{*}$. The equilibrium total post-tax profit then becomes

$$
\Pi=(1-T) \bar{\pi}+(1-t)\left[\frac{(1-c)^{2}}{4}+\frac{\left(1-c_{*}\right)^{2}}{8}\right]
$$

\footnotetext{
${ }^{30} \delta$ is bounded above by $\bar{\delta} \equiv \min \{\hat{\delta}, \hat{\hat{\delta}}\}$, where $\hat{\delta} \equiv \sup \left\{\delta: t^{* *}>0\right\}$ and $\hat{\hat{\delta}} \equiv \min \{\sup \{\delta: \Pi>0\}, \sup \{\delta$ : $\left.\left.\Pi^{S}>0\right\}\right\}$.
} 
In the separate-location scheme, the total post-tax profit is modified as follows:

$$
\Pi^{S}=(1-T)\left[\left(g^{S}-c\right) q^{S}+\left(g_{*}^{S}-c_{*}\right) q_{*}^{S}\right]+(1-t)\left(p^{S}-g^{S}\right) q^{S} .
$$

The equilibrium input prices are

$$
\begin{aligned}
g^{S} & =c+\frac{(1-c)(t-T)}{t-2 T+1}, \\
g_{*}^{S} & =\frac{1+c_{*}}{2},
\end{aligned}
$$

where we note $g^{S}<g_{*}^{S}$. The equilibrium total post-tax profit is calculated as

$$
\Pi^{S}=(1-T)\left[\bar{\pi}+\frac{\left(1-c_{*}\right)^{2}}{8}+\frac{(1-T)(1-c)^{2}}{4(t-2 T+1)}\right] .
$$

The MNE prefers the co-location scheme if

$$
\begin{aligned}
& \Pi-\Pi^{S}=\frac{(T-t)\left[t\left\{3-2 c(2-c)-c_{*}\left(2-c_{*}\right)\right\}-2 T\left\{(1-c)^{2}+\left(1-c_{*}\right)^{2}\right\}+\left(1-c_{*}\right)^{2}\right]}{8(t-2 T+3)}>0, \\
& \rightarrow t>t^{*} \equiv \frac{2 T\left[(1-c)^{2}+\left(1-c_{*}\right)^{2}\right]-\left(1-c_{*}\right)^{2}}{3-2 c(2-c)-c_{*}\left(2-c_{*}\right)} .
\end{aligned}
$$

where we can confirm $t^{*} \in(0, T)$ if $T$ is sufficiently large:

$$
T>\bar{T} \equiv \max \left\{\frac{1}{4}, \frac{\left(1-c_{*}\right)^{2}}{2\left[(1-c)^{2}+\left(1-c_{*}\right)^{2}\right]}\right\} .
$$

The co-location scheme is chosen if the host's tax rate is close to the parent's $\left(t \in\left(t^{*}, T\right)\right)$ and the separate-location scheme is chosen otherwise $\left(t \in\left(0, t^{*}\right]\right)$ as in Proposition 1.

ALP Case. In the co-location scheme, the transfer price $\tilde{g}$ must be within the range of $\left[\tilde{g}_{*}-e, \tilde{g}_{*}+e\right]$ with $e>0$. We assume $e$ is not too large, otherwise the situation is reduced to the benchmark case. The MNE sets the price $\tilde{g}_{*}$ to the local firm and $\tilde{g}=\tilde{g}_{*}+\tilde{e}$ to the downstream affiliate, where $\tilde{e} \in[-e, e]$. It chooses $\tilde{g}_{*}$ and $\tilde{e}$ to maximize the total post-tax profit:

$$
\max _{\tilde{g}_{*}, \tilde{e}} \widetilde{\Pi}=(1-T) \bar{\pi}+(1-t)\left[\left(\tilde{g}_{*}+\tilde{e}-c\right) \tilde{q}+\left(\tilde{g}_{*}-c_{*}\right) \tilde{q}_{*}+\left(\tilde{p}-\tilde{g}_{*}-\tilde{e}\right) \tilde{q}\right]
$$

noting that the optimal outputs $\left(\tilde{q}, \tilde{q}_{*}\right)$ chosen by the downstream firms are the same as those in the text.

As the fact that $g<g_{*}$ holds in the benchmark case suggests, the MNE tries to set $\tilde{g}$ lower 
than $\tilde{g}_{*}$ and thus chooses $\tilde{e}=-e$. The equilibrium input prices are

$$
\begin{aligned}
& \tilde{g}_{*}=\frac{1+c+c_{*}+e}{3}, \\
& \tilde{g}=\tilde{g}_{*}-e=\frac{1+c+c_{*}-2 e}{3} .
\end{aligned}
$$

The total post-tax profit can then be rewritten as

$$
\widetilde{\Pi}=(1-T) \bar{\pi}+(1-t)\left[\frac{\left(2-c-c_{*}\right)^{2}}{12}-\frac{e\left(1-2 c+c_{*}+e\right)}{6}\right] .
$$

In the separate-location scheme, we can analogously define the total post-tax profit and compute the equilibrium input prices as follows:

$$
\begin{aligned}
& \tilde{g}_{*}^{S}=\frac{1+c+c_{*}+e}{3}+\frac{\left(2-c-c_{*}+2 e\right)(t-T)}{3(t-4 T+3)} \\
& \tilde{g}^{S}=\tilde{g}_{*}^{S}-e=\frac{1+c+c_{*}-2 e}{3}+\frac{\left(2-c-c_{*}+2 e\right)(t-T)}{3(t-4 T+3)}
\end{aligned}
$$

where the MNE sets $\tilde{e}=-e$ as implied by $g^{S}<g_{*}^{S}$. The equilibrium total post-tax profit is calculated as

$$
\begin{aligned}
& \widetilde{\Pi}^{S}=(1-T)\left[\bar{\pi}+\frac{(1-T)\left(2-c-c_{*}\right)^{2}-2 e\{e(t-2 T+1)+\kappa\}}{4(t-4 T+3)}\right], \\
& \text { where } \kappa \equiv(1-c)(1-t)-\left(c-c_{*}\right)(t-2 T+1) .
\end{aligned}
$$

Taking difference between the post-tax profits in the two schemes gives

$$
\begin{aligned}
& \widetilde{\Pi}-\widetilde{\Pi}^{S}=\frac{H(e)(T-t)}{12(t-4 T+3)}, \\
& \text { where } \begin{aligned}
H(e) \equiv-2(t-6 T+5) e^{2}+2\left[1-t+2 c(t-3 T+2)-c_{*}(t-6 T+5)\right] e \\
\quad+\left(2-c-c_{*}\right)^{2}(t-3 T+2) .
\end{aligned}
\end{aligned}
$$

Since $T-t>0$ and $t-4 T+3>0$ hold, the inequality is positive if $H(e)>0$ holds. Noting that $t-6 T+5>0$ and $t-3 T+2>0$ hold because of $(\mathrm{A} 1): t>\underline{t}$, we see that $H(e)$ has a negative coefficient of the quadratic term and that $H(0)>0$. These observations imply that $H(e)>0$ holds if $e \in\left(0, e_{2}\right)$, where $e_{2}$ is the larger root of $H(e)=0$. In other words, if the degree of input differentiation is so low that the arm's length range is narrow enough, the MNE always chooses the co-location scheme as in Proposition 2. 


\section{A.8. Endogenous Profits in the Parent Market}

In the text, we assume that the MNE earns exogenous profits $\bar{\pi}$ from different business in the parent country. Here we endogenize it by introducing a local downstream firm in the parent. The local firm is the monopolist facing the demand curve of $P_{*}=1-Q_{*}$. It sources the same type of inputs as do the downstream firms in the host, from the upstream affiliate at the price of $G_{*}$. As the parent's and the host's markets are segmented, the presence of the local firm does not affect the equilibrium outputs and input prices for the downstream firms in the host. It only affects the location choice of the MNE, as we shall see below.

Benchmark Case. In the co-location scheme, the total post-tax profit is modified as

$$
\Pi=(1-t)\left[(g-c) q+\left(g_{*}-c\right) q_{*}+\left(G_{*}-c\right) Q_{*}+(p-g) q\right],
$$

where the optimal outputs $\left(q, q_{*}\right)$ chosen by the downstream firms are the same as those in the text: $q=(1-g) / 2 ; q_{*}=\left(1-g_{*}\right) / 2$. We also note $Q_{*}=\left(1-G_{*}\right) / 2$. The equilibrium input prices to maximize it are given by

$$
\begin{aligned}
& g=c, \\
& g_{*}=G_{*}=\frac{1+c}{2} .
\end{aligned}
$$

The equilibrium total post-tax profit then becomes

$$
\Pi=\frac{(1-t)(1-c)^{2}}{2}
$$

In the separate-location scheme, the total post-tax profit is modified as follows:

$$
\Pi^{S}=(1-T)\left[\left(g^{S}-c\right) q^{S}+\left(g_{*}^{S}-c\right) q_{*}^{S}+\left(G_{*}^{S}-c\right) Q_{*}^{S}\right]+(1-t)\left(p^{S}-g^{S}\right) q^{S}
$$

The equilibrium input prices are

$$
\begin{aligned}
& g^{S}=c+\frac{(1-c)(t-T)}{t-2 T+1}, \\
& g_{*}^{S}=G_{*}^{S}=\frac{1+c}{2} .
\end{aligned}
$$

The equilibrium total post-tax profit is calculated as

$$
\Pi^{S}=\frac{(1-T)(1-c)^{2}(t-3 T+2)}{4(t-2 T+1)} .
$$

The profit difference takes a complex form and is hard to characterize analytically. We thus rely on numerical simulations. Fig. A1 draws the total post-tax profits in the two schemes 
for different levels of the host's tax rate. ${ }^{31}$ In Fig. A1.(a), where the parent's tax rate is high $(T=0.35)$, the separate-location scheme is chosen for $t \in\left(0, t^{*}\right)$ and the co-location scheme for $t \in\left[t^{*}, T\right)$. In Fig. A1.(b), where the parent's tax rate is low $(T=0.2)$, the co-location scheme is chosen for the entire range $t \in(0, T)$. We have experimented various parameter values and confirmed the qualitatively same results as in Proposition 1. That is, the higher the parent's tax rate is, the more likely we are to observe the separate-location scheme as Fig. A1.(a) shows.

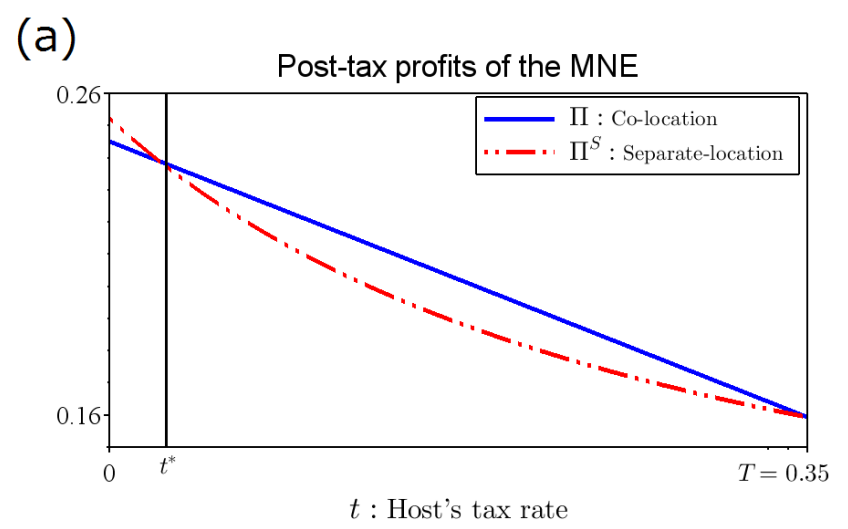

(b)

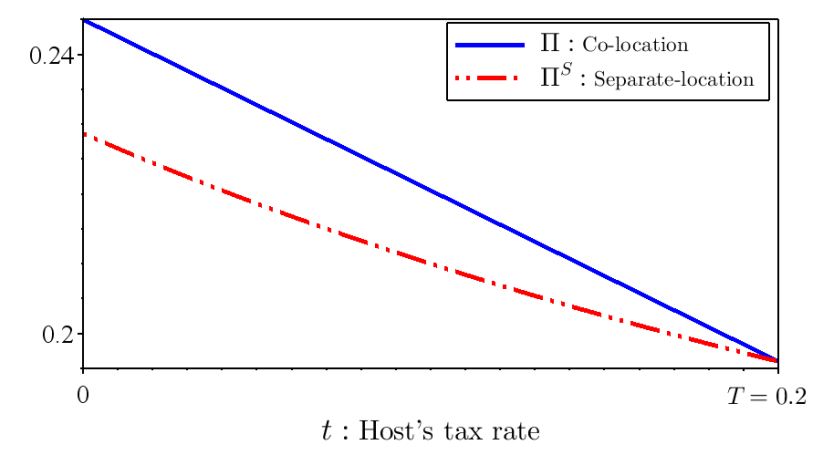

Fig. A1. Production location choice in the benchmark case: (a) high $T$ and (b) low $T$

ALP Case. Analogous to the benchmark case, the equilibrium input price in the co-location scheme is derived as follows:

$$
\tilde{g}=\tilde{g}_{*}=\tilde{G}_{*}=\frac{1+2 c}{3}
$$

\footnotetext{
${ }^{31}$ The parameter values are the same as those in Fig. $1: c=0.3 ;(\mathrm{a}) T=0.35 ;(\mathrm{b}) T=0.2$. In this numerical example, $\underline{t}=0$ holds.
} 
The associated total post-tax profit becomes

$$
\widetilde{\Pi}=\frac{(1-t)(1-c)(5-8 c)}{9} .
$$

To make $\widetilde{\Pi}$ positive, we assume $c<5 / 8$.

In the separate-location scheme, the equilibrium input prices and the resulting total posttax profit are

$$
\tilde{g}^{S}=\tilde{g}_{*}^{S}=\tilde{G}_{*}^{S}=\frac{1+2 c}{3}+\frac{2(1-c)(t-T)}{3(t-4 T+3)} .
$$

The associated total post-tax profit becomes

$$
\widetilde{\Pi}^{S}=\frac{2(1-T)^{2}(1-c)^{2}(t-3 T+2)}{(t-4 T+3)^{2}} .
$$

Because the profit difference is difficult to characterize analytically, we again use numerical simulations. Fig. A2 illustrates the total post-tax profits in the two schemes for different levels of the host's tax rate. ${ }^{32}$ Unlike the benchmark case, the co-location scheme is chosen for the entire range even when the parent's tax rate is high. We have conducted many simulations and confirmed that the ALP prevents the MNE from choosing the separate-location scheme as in Proposition 2.

\footnotetext{
${ }^{32}$ The parameter values are the same as those in Fig. $1: c=0.3 ;(\mathrm{a}) T=0.35 ;(\mathrm{b}) T=0.2$.
} 


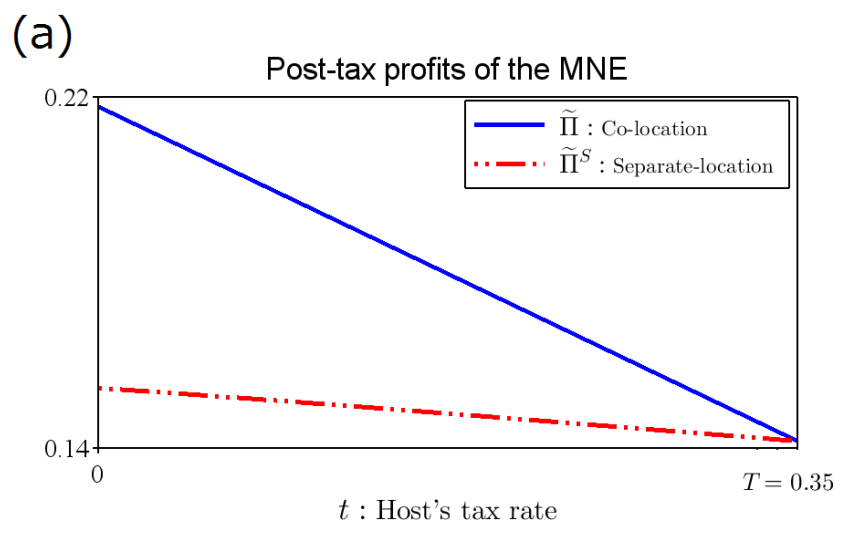

(b)

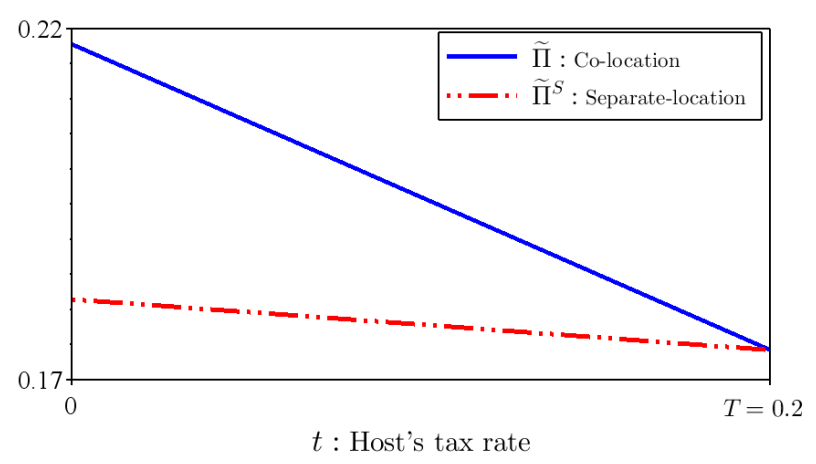

Fig. A2. Production location choice in the ALP case: (a) high $T$ and (b) low $T$

\section{A.9. Welfare Analysis}

We confirm here that the results on tax revenues stated in Proposition 3 carry over to social welfare. That is, the location change induced by the ALP decreases the host country welfare, while increases global welfare.

Host Country Welfare. Assuming $T>1 / 4$, we show that when $t \in\left(\underline{t}, t^{*}\right)$, the social welfare of the host country in the benchmark case, $W_{H}$, are greater than that in the ALP case, $\widetilde{W}_{H}$. $W_{H}$ and $\widetilde{W}_{H}$ are defined as follows:

$$
\begin{aligned}
& W_{H}=\underbrace{\frac{\left(q^{S}\right)^{2}}{2}+\frac{\left(q_{*}^{S}\right)^{2}}{2}}_{\text {Consumer surplus }}+\underbrace{(1-t)\left(\pi^{S}+\pi_{*}^{S}\right)}_{\text {Producer surplus }}+\underbrace{t\left(\pi^{S}+\pi_{*}^{S}\right)}_{\text {Tax revenues }}, \\
& \widetilde{W}_{H}=\underbrace{2 \times \frac{\tilde{q}^{2}}{2}}_{\text {Consumer surplus }}+\underbrace{(1-t)\left(\tilde{\pi}_{u}+2 \tilde{\pi}\right)}_{\text {Producer surplus }}+\underbrace{t\left(\tilde{\pi}_{u}+2 \tilde{\pi}\right)}_{\text {Tax revenues }},
\end{aligned}
$$

where we note $\tilde{q}=\tilde{q}_{*}$ and $\tilde{\pi}=\tilde{\pi}_{*}$. 
Taking the difference of these two gives

$$
\widetilde{W}_{H}-W_{H}=\left[\tilde{q}^{2}-\frac{\left(q^{S}\right)^{2}+\left(q_{*}^{S}\right)^{2}}{2}\right]+\underbrace{\left[\tilde{\pi}_{u}+2 \tilde{\pi}-\left(\pi^{S}+\pi_{*}^{S}\right)\right]}_{(-)} .
$$

As we know from Proposition 3 that the second square bracket term is negative, it suffices to check the first square bracket term is negative:

$$
\begin{aligned}
& \tilde{q}^{2}-\frac{\left(q^{S}\right)^{2}+\left(q_{*}^{S}\right)^{2}}{2}=\frac{(1-c)^{2} f(t)}{288(t-2 T+1)^{2}}, \\
& \text { where } f(t) \equiv 23 t^{2}+46(1-2 T) t+56 T^{2}-20 T-13 .
\end{aligned}
$$

This is negative if $f(t)<0$. We can confirm $f(t)<0$ by noting that (i) $f(t)$ is monotonically increasing in $t$ for $t \in\left(\underline{t}, t^{*}\right)$ and (ii) $f(t)$ takes a negative value at the two endpoints of $\underline{t}$ and $t^{*}$. The host country attains a higher consumer surplus under no regulation than under the ALP. Without the ALP, the lower transfer price helps the downstream affiliate reduce its price, benefiting the host's consumers more.

We can thus conclude that the location change triggered by the ALP reduces the host country welfare.

Global Welfare. We show that global welfare under no regulation is higher than that under the ALP for $t \in(\underline{t}, \hat{t})$, where $\hat{t}$ is smaller than $t^{*}$. Let $W_{P}$ (or $\widetilde{W}_{P}$ ) be the social welfare of the parent country under the regulation (or under the ALP), which are given by

$$
\begin{aligned}
& W_{P}=\underbrace{T\left(\bar{\pi}+\pi_{u}^{S}\right)}_{\text {Producer surplus }}+\underbrace{(1-T)\left(\bar{\pi}+\pi_{u}^{S}\right)}_{\text {Tax revenues }}, \\
& \widetilde{W}_{P}=\underbrace{T \bar{\pi}}_{\text {Producer surplus }}+\underbrace{(1-T) \bar{\pi}}_{\text {Tax revenues }} .
\end{aligned}
$$

Global welfare is defined as the sum of the host's and parent's social welfare. Comparing the global welfare under the ALP with that under no regulation yields

$$
\begin{aligned}
\widetilde{W}_{P}+\widetilde{W}_{H}-\left(W_{P}\right. & \left.+W_{H}\right)=\bar{\pi}+\tilde{q}^{2}+\tilde{\pi}_{u}+2 \tilde{\pi}-\left[\bar{\pi}+\frac{\left(q^{S}\right)^{2}+\left(q_{*}^{S}\right)^{2}}{2}+\pi_{u}^{S}+\pi^{S}+\pi_{*}^{S}\right] \\
& =\frac{(1-c)^{2} h(t)}{288(t-2 T+1)^{2}},
\end{aligned}
$$

where $h(t) \equiv 97 t^{2}+2(25-122 T) t+136 T^{2}-28 T-11$.

This is positive if $h(t)>0$. We can confirm $h(t)=0$ at $t=\hat{t} \in\left(\underline{t}, t^{*}\right)$ by noting that (i) $h(t)$ is monotonically decreasing in $t$ for $t \in\left(\underline{t}, t^{*}\right.$ ), (ii) $h(\underline{t})>0$, and (iii) $h\left(t^{*}\right)<0$.

We can conclude that if the international tax difference is sufficiently large $(t \in(\underline{t}, \hat{t}))$, the location change induced by the ALP increases global welfare, i.e., $\widetilde{W}_{P}+\widetilde{W}_{H}-\left(W_{P}+W_{H}\right)>0$. 


\section{References}

Avi-Yonah, R. S. (2007). The rise and fall of arm's length: A study in the evolution of US international taxation. Law \& Economics Working Papers, University of Michigan Law School.

Bartelsman, E. J. and Beetsma, R. M. (2003). Why pay more? Corporate tax avoidance through transfer pricing in OECD countries. Journal of Public Economics, 87(9):22252252.

Bauer, C. J. and Langenmayr, D. (2013). Sorting into outsourcing: Are profits taxed at a gorilla's arm's length? Journal of International Economics, 90(2):326-336.

Bernard, A. B., Jensen, J. B., Redding, S. J., and Schott, P. K. (2010). Intra-firm trade and product contractibility (long version). NBER Working Paper, 15881.

Bernard, A. B., Jensen, J. B., and Schott, P. K. (2006). Transfer pricing by US-based multinational firms. NBER Working Paper, 12493.

Bjorvatn, K. and Eckel, C. (2006). Policy competition for foreign direct investment between asymmetric countries. European Economic Review, 50(7):1891-1907.

Blonigen, B. A. (2005). A review of the empirical literature on FDI determinants. Atlantic Economic Journal, 33(4):383-403.

Choe, C. and Matsushima, N. (2013). The arm's length principle and tacit collusion. International Journal of Industrial Organization, 31(1):119-130.

Choi, J. P., Furusawa, T., and Ishikawa, J. (2018). Transfer pricing and the arm's length principle under imperfect competition. CESifo Working Paper Series, 7303.

Clausing, K. A. (2003). Tax-motivated transfer pricing and US intrafirm trade prices. Journal of Public Economics, 87(9):2207-2223.

Copithorne, L. W. (1971). International corporate transfer prices and government policy. Canadian Journal of Economics, 4(3):324-341.

Cristea, A. D. and Nguyen, D. X. (2016). Transfer pricing by multinational firms: New evidence from foreign firm ownerships. American Economic Journal: Economic Policy, 8(3):170-202.

Davies, R. B., Martin, J., Parenti, M., and Toubal, F. (2018). Knocking on tax haven's door: Multinational firms and transfer pricing. Review of Economics and Statistics, 100(1):120134.

Egger, P. and Seidel, T. (2013). Corporate taxes and intra-firm trade. European Economic Review, 63:225-242. 
Elitzur, R. and Mintz, J. (1996). Transfer pricing rules and corporate tax competition. Journal of Public Economics, 60(3):401-422.

Ferrett, B. and Wooton, I. (2010). Competing for a duopoly: International trade and tax competition. Canadian Journal of Economics, 43(3):776-794.

Furusawa, T., Hori, K., and Wooton, I. (2015). A race beyond the bottom: The nature of bidding for a firm. International Tax and Public Finance, 22(3):452-475.

Gresik, T. A. and Osmundsen, P. (2008). Transfer pricing in vertically integrated industries. International Tax and Public Finance, 15(3):231-255.

Griffith, R., Miller, H., and O'Connell, M. (2014). Ownership of intellectual property and corporate taxation. Journal of Public Economics, 112:12-23.

Gumpert, A., Hines Jr, J. R., and Schnitzer, M. (2016). Multinational firms and tax havens. Review of Economics and Statistics, 98(4):713-727.

Guvenen, F., Mataloni Jr, R. J., Rassier, D. G., and Ruhl, K. J. (2017). Offshore profit shifting and domestic productivity measurement. NBER Working Paper, 23324.

Hanson, G. H., Mataloni Jr, R. J., and Slaughter, M. J. (2005). Vertical production networks in multinational firms. Review of Economics and Statistics, 87(4):664-678.

Haufler, A. and Mardan, M. (2014). Cross-border loss offset can fuel tax competition. Journal of Economic Behavior $\&$ Organization, 106:42-61.

Haufler, A. and Wooton, I. (1999). Country size and tax competition for foreign direct investment. Journal of Public Economics, 71(1):121-139.

Haufler, A. and Wooton, I. (2006). The effects of regional tax and subsidy coordination on foreign direct investment. European Economic Review, 50(2):285-305.

Hebous, S., Ruf, M., and Weichenrieder, A. J. (2011). The effects of taxation on the location decision of multinational firms: M\&A versus greenfield investments. National Tax Journal, 64(3):817-38.

Horst, T. (1971). The theory of the multinational firm: Optimal behavior under different tariff and tax rates. Journal of Political Economy, 79(5):1059-1072.

Ishikawa, J., Raimondos, P., and Zhang, X. (2017). Transfer pricing rules under imperfect competition. mimeo.

Kant, C. (1988). Foreign subsidiary, transfer pricing and tariffs. Southern Economic Journal, $55(1): 162-170$.

Karkinsky, T. and Riedel, N. (2012). Corporate taxation and the choice of patent location within multinational firms. Journal of International Economics, 88(1):176-185. 
Kato, H. and Okoshi, H. (2017). Production location of multinational firms under transfer pricing: The impact of the arm's length principle. Keio-IES Discussion Paper Series 2017016, Institute for Economics Studies, Keio University.

Keen, M. and Konrad, K. A. (2013). The theory of international tax competition and coordination. In Auerbach, A. J., Chetty, R., Feldstein, M., and Saez, E., editors, Handbook of Public Economics, volume 5, pages 257-328. Elsevier, Oxford.

Keuschnigg, C. and Devereux, M. P. (2013). The arm's length principle and distortions to multinational firm organization. Journal of International Economics, 89(2):432-440.

Kind, H. J., Midelfart, K. H., and Schjelderup, G. (2005). Corporate tax systems, multinational enterprises, and economic integration. Journal of International Economics, 65(2):507-521.

Lanz, R. and Miroudot, S. (2011). Intra-firm trade. OECD Trade Policy Working Papers, 114.

Ma, J. and Raimondos, P. (2015). Competition for FDI and profit shifting. CESifo Working Paper Series, 5153.

Markusen, J. R. (2004). Multinational Firms and the Theory of International Trade. MIT Press, Cambridge, MA.

Navaretti, G. B. and Venables, A. (2004). Multinational Firms in the World Economy. Princeton University Press, Princeton, NJ.

Nielsen, S. B., Raimondos-Møller, P., and Schjelderup, G. (2003). Formula apportionment and transfer pricing under oligopolistic competition. Journal of Public Economic Theory, $5(2): 419-437$.

Nielsen, S. B., Raimondos-Møller, P., and Schjelderup, G. (2008). Taxes and decision rights in multinationals. Journal of Public Economic Theory, 10(2):245-258.

OECD (2017). OECD Transfer Pricing Guidelines for Multinational Enterprises and Tax Administrations 2017. OECD Publishing, Paris.

Samuelson, L. (1982). The multinational firm with arm's length transfer price limits. Journal of International Economics, 13(3-4):365-374.

Schjelderup, G. and Sørgard, L. (1997). Transfer pricing as a strategic device for decentralized multinationals. International Tax and Public Finance, 4(3):277-290.

Slaughter, M. J. (2000). Production transfer within multinational enterprises and American wages. Journal of International Economics, 50(2):449-472.

Swenson, D. L. (2001). Tax reforms and evidence of transfer pricing. National Tax Journal, $54(1): 7-25$. 
Voget, J. (2011). Relocation of headquarters and international taxation. Journal of Public Economics, 95(9):1067-1081.

Wittendorff, J. (2012). Consistency: Domestic vs. international transfer pricing law. Tax Notes International, pages 1127-1134.

Yao, J. T. (2013). The arm's length principle, transfer pricing, and location choices. Journal of Economics and Business, 65:1-13.

Zhao, L. (2000). Decentralization and transfer pricing under oligopoly. Southern Economic Journal, 67(2):414-426. 